\title{
THE FLIP FLOP NOZZLE EXTENDED TO SUPERSONIC FLOWS
}

\author{
Ganesh Raman ${ }^{*}$ \\ Sverdrup Technology Inc. \\ Lewis Research Center Group \\ Brookpark, OH 44142 \\ $A 92-45561$ \\ Michael Hailye ${ }^{\dagger}$ \\ Department of Aerospace Engineering \\ University of Michigan \\ Ann Arbor, MI 48103 \\ Edward J. Rice ${ }^{* *}$ \\ National Aeronautics and Space Administration \\ Lewis Research Center \\ Cleveland, $\mathrm{OH} 44135$
}

\begin{abstract}
$\underline{\text { Abstract }}$
An experiment studying a fluidically oscillated rectangular jet flow was conducted. The Mach number was varied over a range from low subsonic to supersonic. Unsteady velocity and pressure measurements were made using hotwires and piezoresistive pressure transducers. In addition smoke flow visualization using high speed photography was used to document the oscillation of the jet. For the subsonic flip-flop jet it was found that the apparent time-mean widening of the jet was not accompanied by an increase in the mass flux. Fluidically oscillated jets up to a Mach number of about 0.5 have been reported before, but to our knowledge there is no information on fluidically oscillated supersonic jets. It was found that it is possible to extend the operation of these devices to supersonic flows. Most of the measurements were made for a fixed nozzle geometry for which the oscillations ceased at a fully expanded Mach number of 1.58. By varying the nozzle geometry this limitation was overcome and the operation of the device was extended to a fully expanded Mach number of about 1.8. The streamwise velocity perturbation levels produced by this device were much
\end{abstract}

\footnotetext{
* Research Engineer.

† Surnmer student intern.

${ }^{* *}$ Senior Research Engineer, member AIAA.

higher than the perturbation levels that could be produced using conventional excitation sources such as acoustic drivers. In view of this ability to produce high amplitudes, the potential for using a small scale fluidically oscillated jet as an unsteady excitation source for the control of shear flows in full scale practical applications seems promising.

\section{Nomenclature}

B larger dimension of flip-flop attachment

b larger dimension of rectangular slot nozzle

d diameter of feedback tube

f fundamental frequency of oscillation

H smaller dimension of flip-flop attachment

h smaller dimension of rectangular slot nozzle

L length of feedback tube

$\mathrm{L}_{\mathrm{ff}} \quad$ axial dimension of flip-flop nozzle attachment

M Mach number

$\dot{\mathrm{m}} \quad$ mass flux 


\begin{tabular}{|c|c|}
\hline$P_{\mathbf{a}}$ & ambient pressure \\
\hline$P_{0}$ & reservoir pressure \\
\hline $\mathrm{P}_{\mathrm{o}} / \mathrm{P}_{\mathrm{a}}$ & nozzle pressure ratio \\
\hline$P_{\mathrm{s}}$ & $\begin{array}{l}\text { suction pressure in feedback slot and } \\
\text { loop }\end{array}$ \\
\hline$P_{\text {st }}$ & static pressure \\
\hline $\mathrm{P}_{\mathrm{t} 2}$ & pitot tube pressure \\
\hline $\operatorname{Re}$ & Reynolds number \\
\hline S,s & aspect ratio, $B / H, b / h$ \\
\hline $\mathrm{St}(\mathrm{h})$ & Strouhal number, $\operatorname{St}(\mathrm{h})=\mathrm{f}^{*} \mathrm{~h} / \mathrm{U}_{\mathrm{j}}$ \\
\hline $\mathrm{t}$ & time \\
\hline $\mathbf{U}$ & mean velocity \\
\hline$\tilde{\mathrm{u}}$ & coherent component of velocity \\
\hline$u^{\prime}$ & fluctuating component of velocity \\
\hline $\mathrm{w}$ & width of feedback slot \\
\hline $\mathrm{x}$ & axial distance \\
\hline y & transverse distance \\
\hline$y_{1 / 2}$ & half velocity distance from centerline \\
\hline
\end{tabular}

Subscripts:

$\begin{array}{ll}\text { h } & \text { based on } h \\ \text { ff } & \text { fundamental frequency component } \\ \text { 3f } & \begin{array}{l}\text { component at first harmonic of funda- } \\ \text { mental frequency }\end{array} \\ \text { ff } & \text { flip-flop } \\ \text { o or } j & \text { jet exit condition } \\ \text { tl } & \text { total }\end{array}$

$1 \quad$ location before shock

2 location downstream of shock

\section{Introduction}

Unsteady excitation has been widely used as a tool to study shear layer dynamics as well as to control transition, separation, and shear layer mixing. Discrete tone acoustic excitation can increase the spreading rate of a jet under certain conditions. 1,2 Further increases in the spreading rate can be obtained by multi-frequency plane wave excitation. ${ }^{3,4}$ By combining the right type of plane wave and azimuthal mode excitation, a higher spreading rate, and a distortion of the jet cross-section, can be obtained over an extended region. ${ }^{5-7}$ For laboratory research at low speeds, these techniques could be easily implemented using the electromagnetic acoustic driver as a source of unsteady excitation. However, for jets operating at a high Mach number, very high levels of excitation would be required to alter the spreading rate of the jet. In addition, higher turbulence levels representative of full scale jet exhaust require higher levels of excitation. ${ }^{8}$ Therefore, for high speed jets operating under full scale conditions, it appears that acoustic drivers cannot generate levels that are sufficient to excite the jet. It is also clear that the use of acoustic drivers is not practical due to their weight and volume, as well as their power and maintenance requirements.

Some of the limitations of acoustic drivers have been overcome by excitation techniques such as rotating valves, ${ }^{9}$ oscillating vanes, ${ }^{10}$ and self-excitation using counterflow. ${ }^{11}$ However, for practical applications, the excitation technique needs to be simple, yet effective. Several types of practical devices have been developed for jet mixing enhancement, such as the self exciting "whistler-nozzle"12,13 and the screech-excited jet. 14,15 The "whistler-nozzle" works well for subsonic flows, but ceases to work beyond sonic conditions. ${ }^{12}$ The ability to enhance mixing of a supersonic jet by using its own screech tones has recently received renewed attention due to interest in high speed jet mixing. ${ }^{16}$ 
The present work focusses on the fluidically oscillated nozzle, ${ }^{17,18}$ which seems promising as an excitation device for practical flows. The operation of the fluidically oscillated nozzle is based on that of a bistable fluidic amplifier. The concept is easily understood by considering a rectangular jet issuing into the region between two plates. Despite the symmetry, the jet may attach to one of the walls (Coanda effect), and a small pressure gradient could cause the jet to detach from one wall and attach to the other. If this process could be controlled and repeated periodically, the result is an oscillating jet flow. Details of the operation of such nozzles can be found in a paper by Viets. ${ }^{17}$ The fluidic nozzle can be used to produce a time dependent flow with a substantial change in the time-averaged jet half-width spreading rate. ${ }^{17,18}$

It needs to be emphasized that the Strouhal number range over which the flip-flop nozzle operates is 1 to 2 orders of magnitude below the Strouhal number range of the natural flow instability. Figure 1, which is adapted from Rockwell, ${ }^{10}$ shows the domains of excited jets on a map of $S t(h)$ versus $\operatorname{Re}(h)$. At a very high $\mathrm{St}(\mathrm{h})$, artificial excitation results in turbulence suppression. ${ }^{19,20}$ The $\mathrm{St}(\mathrm{h})$ ranging from 0.1 to 0.6 , is the regime of mixing enhancement by the forced pairing of vortices. ${ }^{1-4}$ This is also the regime of operation of the "whistler nozzle" and the domain of the screech tones in a supersonic jet. The region over which the flip-flop nozzle operated in the present study is also shown in Fig. 1. This low Strouhal number oscillation of the entire jet is actually equivalent to a periodic displacement of the entire jet shear layer. In developing a flip-flop nozzle that could be used as an excitation device, the ultimate objective would be to match the Strouhal number of the oscillation of the flip-flop nozzle with the Strouhal number of the natural instability of the flow being excited.

The objective of this paper is to extend the operation of fluidically oscillated nozzles to supersonic flows. Previous research has only documented the operation of the fluidically oscillated jet up to the mid subsonic Mach number range.
For applications such as supersonic mixer ejectors it is of interest to study fluidic nozzles operating at supersonic speeds. The present study is motivated by the need for developing excitation devices for the control of shear flows in practical applications. There are several advantages to using the fluidic nozzle as an excitation device. It has no moving parts, and in addition to producing very high levels of streamwise velocity perturbation, the oscillating flow is selfsustaining. ${ }^{17}$

\section{Experimental Details}

The jet facility consisted of a plenum tank to which various types of nozzles could be attached. The tank was supplied by compressed air at pressures up to 45 psig. Figure 2 shows a schematic of the fluidic nozzle and its various parts. Figures 2(a) and (b) represent the assembled and exploded views, respectively. The nozzle has 3 parts: the rectangular converging slot nozzle, a nozzle attachment with control ports, and a feedback tube that connects the control ports. The exit (centerline) of the inner rectangular nozzle is the origin of the coordinate system shown in Fig. 2.

In Fig. 2, the smaller and larger exit dimensions of the rectangular slot nozzle are denoted by lower case $h$ and $b$, respectively, while the corresponding dimensions for the flip-flop nozzle attachment are denoted by upper case $\mathrm{H}$ and $\mathrm{B}$ respectively. The width of the control port and the extent of the flip-flop attachment beyond the control port are denoted by $\mathrm{w}$ and $\mathrm{L}_{\mathrm{ff}}$, respectively. Note that the control port is present right at the exit of the inner nozzle. Four different nozzle geometries were investigated and they are referred to as nozzles I, II, III, and IV. For nozzles I, II, and III, the outer flip-flop attachment has a rectangular (parallel wall) geometry. For these nozzles, the step between the inner rectangular slot nozzle and the outer flip-flop attachment in the $y$-direction is denoted by $\mathrm{h}_{\mathrm{s}}=(\mathrm{H}-\mathrm{h}) / 2$. The dimension of this step will be shown in later sections to be a parameter crucial for the oscillation of the flip-flop jet at higher Mach numbers. The numerical values of the 
geometric parameters shown in Fig. 2 are summarized in Table 1 for the various nozzles tested. The nozzles used in the present work are essentially adaptations of the original Viets ${ }^{17}$ design. Nozzle I, which has the largest dimensions, was used for the subsonic tests. Nozzles II and III differ only in the step height, $\mathrm{h}_{\mathrm{s}}$. Nozzle IV, which has the same step height as nozzle II, has a divergent flip-flop attachment with a half angle of 5 degrees. It should be noted that the step, $h_{s}$, between the inner slot nozzle and the outer flipflop attachment was present only in the y-direction (Fig. 2). In the z-direction for all nozzles, the parallel side walls of the flip-flop attachment are flush with the inner slot nozzle surface.

Measurements in the flowfield were made using standard hot-wire probes up to an axial distance of $x / h=15$. For the supersonic exit conditions, the hot-wires were only positioned in the subsonic portions of the flow. A total pressure probe $(0.8 \mathrm{~mm}$ o.d.) was used to survey the flowfield. In order to measure the static pressure a special double-cone probe $(1 \mathrm{~mm}$ o.d.) was used. This probe was previously used in a separate study by Zaman et al. ${ }^{21}$ and is based on the design of Pinckney. ${ }^{22}$ The pressure ports in the probe were located $3.5 \mathrm{~mm}$ downstream of the tip. For the measurement of the oscillating static pressure in the feedback tube, two piezoresistive pressure transducers mounted on either side of the feedback tube were used. A vacuum pump was used to calibrate these transducers for the measurement of sub-atmospheric pressures $(0$ to 15 psia). A pressure port in the feedback tube was used to measure the mean static pressure (Fig. 2). A $0.64 \mathrm{~cm}$ (B \& K) microphone was used to obtain sound pressure levels and spectra for the supersonic flow cases. For these measurements, the microphone was located slightly behind the nozzle, very close to the nozzle lip.

\section{Results and Discussion}

\subsection{The Subsonic Flip-Flop Jet}

\subsubsection{Flow Visualization}

Flow visualization using smoke and high speed photography was used to capture the details of the low frequency oscillatory behavior. The high speed $16 \mathrm{~mm}$ movie camera was capable of reaching speeds as high as $\mathbf{5 0 0}$ frames/sec. At $\mathrm{M}=0.3$, the camera speed, though not high enough to capture the unsteadiness due to turbulence or shear layer vortices $(\mathrm{St}(\mathrm{h})=0.2$, $\mathrm{f}=4000 \mathrm{~Hz}$ for nozzle I), was adequate to provide a record of the low frequency oscillation of the entire jet $(\mathrm{St}(\mathrm{h})=0.005, \mathrm{f}=100 \mathrm{~Hz})$.

Figure 3 shows flow visualization photographs for the subsonic rectangular slot nozzle (a) as well as for the flip-flop jet nozzle (b). The pictures are stills from a high speed $16 \mathrm{~mm}$ movie made at a Mach number of 0.3 . The visualization of the jet was made possible by filling the entire plenum chamber with smoke. The "whipping" action caused by the flip-flop device is seen in Fig. 3(b). Approximately one wavelength is visible. The photograph shows the region up to an $x / h$ of about 50 from the nozzle exit.

\subsubsection{Time-Mean Spreading and Entrainment}

Figure 4 shows the time-mean velocity profiles for the rectangular slot nozzle and the flip-flop jet (nozzle I, Table 1 ) at various $\mathrm{x} / \mathrm{h}$ locations at $M=0.2$. It should be noted that the profiles are staggered vertically in proportion to the axial distance at which they were measured. At first glance, the flip-flop jet is seen to have a higher time-mean transverse spread and a wider time-mean spreading angle. The point to be made here is that this does not necessarily imply mixing enhancement in all cases. The time-mean velocity profiles here are dependent mainly on the extent of the displacement of the entire jet between its two extremes, thus, the time-mean velocity profile is a misleading indicator of jet mixing. The same can be said for the half velocity coordinate. For a better estimate of mixing enhancement one would have to calculate the mass flux. The mass flux was calculated by integrating the velocity profiles shown in Fig. 4. The velocity profiles were integrated from the centerline, up to the point where the local velocity was 10 percent of the centerline velocity. From Figs. 5(a) and (b) it can be seen that even though the half velocity spreading rate 
for the flip-flop jet is much higher than that of the rectangular slot nozzle (Fig. 5(a)), the mass flux ratio for both jets is about the same (Fig. 5(b)).

The mass flux calculations depend considerably on where the integration is terminated in the $y$ direction. To ensure that the mass flux trends reported in Fig. 5(b) were not dependent on the integration boundary, the integrations were performed up to the points where the velocity was $20,15,10$, and 5 percent of the centerline velocity. As one would expect, the farther the integration proceeded the greater was the mass flux for both the flip-flop nozzle and the rectangular slot nozzle. However, the conclusions made from Fig. 5 are valid for all integration boundaries, namely, the dramatic change in the time-mean spreading angle for the flip-flop jet seen in the half-velocity data (Fig. $5(a)$ ) is deceptive and is not accompanied by a significant increase in the mass flux (Fig. 5(b)). This observation is corroborated by the findings of Simmons et al. ${ }^{23}$ Fiedler and Korschelt, ${ }^{24}$ and Srinivas et al. ${ }^{25}$ Srinivas et al. ${ }^{25}$ concluded that the flip-flop nozzle, while being a good flow spreading device, is not so effective in entrainment.

\subsubsection{Potential for use as an Unsteady Fluid Dynamic Excitation Device}

Figure 6 shows the radial variation of phase averaged unsteady velocity components from the jet centerline to the outer edge of the jet (in the $y$ direction) for three $\mathrm{x} / \mathrm{h}$ locations. The velocity fluctuations are shown at the fundamental oscillation frequency of the flip-flop nozzle $\left(\widetilde{u}_{f}\right)$, along with components at its harmonics $\left(\tilde{u}_{2 f}, u_{3 f}\right)$. The magnitudes of the higher harmonics are small compared to that of the fundamental component. The total rms fluctuation level in the jet $\left(u_{t l}^{\prime}\right)$ is also shown for comparison. The fundamental fluctuation level $\left(\tilde{u}_{\mathrm{f}}\right)$ close to the jet exit $(\mathrm{x} / \mathrm{h}=0.3)$ is low at the jet centerline $(y=0)$ and peaks around $\mathrm{y} / \mathrm{h}=0.6$. All components of the fluctuating velocity are seen to decay with downstream distance.
The strong streamwise velocity fluctuation levels for the flip-flop jet are essentially due to the oscillation of the jet between its two extremes. However, there still remains the potential for using the flip-flop jet as an unsteady fluid dynamic excitation device. For a flipflop jet operating at a Mach number of 0.3 the amplitude of the velocity fluctuations at the fundamental frequency ranges from a maximum of 40 percent of the mean velocity at the jet exit (Fig. 6(a)) to 10 percent at $x / h=26$ (Fig. 6(c)). In contrast, the streamwise velocity perturbations that could be produced using acoustic drivers with a power rating of $40 \mathrm{~W}$ were in the range of 1 to 3 percent of the mean velocity, the higher value attainable only with the help of plenum resonances. ${ }^{8}$ Even a high amplitude Ling electro-pneumatic driver could only produce levels up to 7 percent of the jet velocity at the nozzle exit plane. ${ }^{4}$ Thus, the main merits of the flip-flop jet lie in its ability to produce high amplitudes of streamwise velocity perturbation levels, which could be used to excite other flows.

\subsection{The Extension to Supersonic Flows}

\subsubsection{Flow Visualization}

Stills from the smoke flow visualization using high speed photography for the supersonic jet are shown in Figs. 7(a) to (c) for nozzle II of Table 1. For the smoke flow visualization of the supersonic jet, a smoke injection technique different from that of Fig. (3) was used. A pair of tubes were used to inject smoke at the jet exit. The dual tube smoke injection technique was controlled by the flapping of the jet. When the jet flapped to the bottom it entrained smoke from the bottom tube (Fig. $7(\mathrm{a})$ ). When the jet flapped to the top it entrained smoke from the top tube (Fig. 7(b)). Thus the flapping of the jet was made visible by the alternate discharge of smoke from the tubes. The two phases of oscillation at $M=1.58$ are shown in the photographs in Figs. 7(a) and (b) alongside sketches. Figure $7(\mathrm{c})$ shows the case at $\mathrm{M}=1.90$ when the flip-flop jet had stopped oscillating. Here the flow from the inner slot jet is attached to both walls of the flip-flop attachment and the smoke from both tubes is seen to be entrained by the high speed jet. 
3.2.2 Distinguishing Features of the Supersonic Flip-Flop Nozzle

It should be noted that for the underexpanded convergent rectangular nozzle used in this experiment, the Mach numbers quoted are the fully expanded Mach numbers. In other words, the Mach number attained if the flow had isentropically expanded to ambient room pressure. However, for the flip-flop nozzles, the pressure at the control ports is sub-atmospheric (approximately 6 psia at $\mathrm{M}=1.9$ ). The situation is similar to that of a blocked ejector (secondary inlets closed). Due to this reduced pressure, the supersonic jet actually exits into sub-atmospheric surroundings, resulting in a much higher local jet Mach number. Figure 8(a) shows the magnitude of the low pressures measured in the feedback tube at various upstream reservoir pressures. Data are shown for nozzles II, III, and IV. Most of the measurements presented in this paper were obtained for nozzle II (Table 1). For this nozzle the pressure was measured both at the step between the inner slot nozzle and the outer flip-flop attachment and in the feedback tube (see sketch in Fig. 8). The pressures at these two locations were found to be approximately the same (Fig. 8(a), nozzle II step and feedback tube). Nozzle II stops oscillating around $\mathrm{P}_{\mathrm{o}} / \mathrm{P}_{\mathrm{a}}=3$. When the jet stops oscillating and is attached to both walls the value of $\mathrm{P}_{\mathrm{s}} / \mathrm{P}_{\mathrm{a}}$ drops further from 0.6 to 0.45 .

The Mach number for the flip-flop nozzles which takes into account the reduced pressure is plotted in Fig. 8(b) for nozzles II, III, and IV. For each nozzle the value of $P_{s} / P_{0}$ was used in conjunction with the isentropic relationship to calculate $M$. A curve for the rectangular slot nozzle obtained using $\mathrm{P}_{\mathrm{a}} / \mathrm{P}_{\mathrm{o}}$ in the isentropic relationship (fully expanded Mach number) is also shown for comparison. A very interesting point to be noted here is that for the same tank pressure the Mach number with the flip-flop attachment present is higher than that for the rectangular nozzle alone. In other words, for a prescribed Mach number the reservoir pressure required is lowered by the attachment of the flipflop device. As mentioned in connection with Fig. 8(a), when flip-flop nozzle II stops oscillating, the Mach number suddenly increases to 1.9 , due to the sudden decrease in $\mathrm{P}_{\mathrm{s}}$.
Hot-wire time series data are shown for Mach numbers ranging from low subsonic $(\mathrm{M}=0.68)$ to supersonic $(\mathrm{M}=1.90)$ in Fig. 9(a) for nozzle II (Table 1). Due to difficulties in the use of hot-wires at high subsonic and supersonic speeds it was not possible to document the type of measurements presented for the $M=0.3$ jet in Fig. 6. Instead, for the high Mach number cases, the hot-wire was located at the $M=0.5$ location in the shear layer at the jet exit plane. As the jet Mach number was increased, the hotwire had to be moved in the $y$ direction away from the jet centerline in order to stay at the local $\mathrm{M}=0.5$ location. For this reason, it is not proper to make quantitative comparisons of the oscillation amplitudes at various jet Mach numbers. The results presented in Fig. 9(a) are therefore to be regarded as being qualitative. The velocity signal clearly shows the quasisquare wave behavior of this bistable device. As mentioned in connection with Fig. 6, the large velocity fluctuations are a result of the transverse oscillation of the jet between its two extremes. Strong velocity oscillations are seen up to a Mach number of 1.58 beyond which the oscillations cease. As observed in the smoke flow visualization at a Mach number slightly above 1.58 the flip-flop nozzle stopped oscillating due to the inner slot jet attaching to both walls of the flip-flop nozzle. This results in a further decrease in the static pressure at the step and as a consequence the Mach number abruptly jumps to 1.9 .

Figure 9(b) shows the unsteady oscillating pressure measured using one of the piezoresistive pressure transducers within the feedback tube. The location of this sensor is shown in Fig. 2. The oscillations here are quasi-sinusoidal and occur at the same primary frequency as the velocity oscillations detected by the hot-wire in Fig. 9(a). Simultaneous measurements of the unsteady pressures from both the pressure transducers mounted on either side of the feedback tube showed the signals to be $180^{\circ}$ out of phase. The amplitudes of the pressure oscillations were of the order of 1 psi (rms) and 2 psi (peak to peak) when the Mach number was 1.58. It was this periodic 2 psi pressure difference between the two control ports that sustained the oscillation of the jet by causing the inner jet to alternately attach and detach from the two outer 
plates. At the same Mach number $(\mathrm{M}>1.58)$ where the velocity oscillations in the shear layer cease, the pressure oscillations in the feedback tube were seen to do the same.

\subsubsection{Dependence of Flip-Flop Frequency on} Mach number

The frequency versus Mach number relationship for the various high speed nozzles tested is shown in Fig. 10. From Fig. 10 it is seen that the oscillation of the flip-flop jet extends smoothly from subsonic to supersonic flows. For a fixed feedback tube length and diameter the frequency of oscillation of the flip-flop nozzle was seen to increase with an increase in the Mach number. The frequencies varied from $30 \mathrm{~Hz}$ at $\mathrm{M}=0.1$ to about $300 \mathrm{~Hz}$ at $\mathrm{M}=1.58$. For nozzle II, the oscillations ceased at a Mach number of 1.58 as explained in earlier sections due to the attachment of the inner slot jet to both walls of the flip-flop attachment. By increasing the flip-flop nozzle step height (nozzle III) this limitation was overcome and the operation of the flip-flop nozzle was extended to $\mathrm{M}=1.8$, at which condition, the inner slot jet flow expanded and attached to both walls of the flip-flop nozzle. Another nozzle that was briefly looked at was nozzle IV, which had the same step height, $h_{g}$, as nozzle II but with a divergent flip-flop attachment with a half angle of 5 degrees. Nozzle IV was also seen to stop oscillating around $\mathrm{M}=1.58$. It can be concluded from these observations that the step $\left(h_{s}\right)$ between the inner slot nozzle and the outer flip-flop attachment is the strongest parameter that determines the Mach number at which the flip-flop nozzle stops oscillating.

It should be pointed out that despite the apparent similarity in geometry (due to the step $h_{s}$ ) between the flip-flop nozzle and the "whistler" nozzle, the principle of operation of these two devices differs significantly. The "whistler" excitation is the result of a coupling between a shear layer tone and duct resonance of the nozzle. ${ }^{13}$ It needs to be emphasized that for the results presented in this paper, there is no "whistler" type of effect superimposed on the flip-flop jet. According to Hill and Greene ${ }^{12}$ a two-dimensional whistler cannot function. Special cases of the non-axisymmetric whistler can be made to work if the aspect ratio is small $(\sim 3)$ and if an outward step is present in the $y$ and $z$ dimensions. In the present experiment, a high aspect ratio rectangular nozzle was used $(\sim 8)$ and the outward facing step was only present in the $y$ direction. In addition, the whistler nozzle ceases to work beyond sonic conditions, whereas the flip-flop nozzle continues to operate at supersonic speeds. As discussed earlier in connection with Fig. 1, the whistler frequency is approximately in the range of $\mathrm{St}(\mathrm{h})=0.1$ to 0.6 , which is the regime of jet coherent structure amplification and mixing enhancement by forced mergings. In the present experiment, the hot-wire and microphone spectra only showed peaks corresponding to the flip-flop jet oscillation and its harmonics $(\mathrm{St}(\mathrm{h})=0.0005-0.01)$ which are 1 to 2 orders of magnitude below the whistler frequency. These findings are considered sufficient evidence to rule out any "whistler" excitation being superimposed on the flip-flop jet.

\subsubsection{Axial Variation of Pressures and Local} Mach Number Within the Flip-Flop Nozzle

Figure 11 shows pitot pressure measurements obtained using a pitot probe on the jet centerline within the flip-flop nozzle, and data from the corresponding locations for the rectangular nozzle without the flip-flop attachment. In this section and the following sections the flipflop nozzle is compared to the rectangular slot nozzle operating at the same nozzle pressure ratio. Figures 11(a) and (b) represent nozzle pressure ratios of 2.75 and 3.65. At a nozzle pressure ratio of 2.75 (Fig. 11(a)), the Mach numbers for the rectangular slot nozzle and the flip-flop nozzle are 1.3 and 1.58 respectively, whereas at a nozzle pressure ratio of 3.65 the corresponding Mach numbers are 1.5 and 1.9 respectively. (The reason for the difference in Mach numbers at the same nozzle pressure ratio was explained in section 3.2.2.). Figure 11(a) represents the case where the flip-flop jet is oscillating, whereas Fig. 11(b) represents the case where the flip-flop jet has stopped oscillating and is attached to both walls of the flip-flop attachment. It should be noted that the local pressures are influenced significantly by the shock/ expansion process and the complex threedimensional flow within the flip-flop device. For the rectangular slot nozzle the peaks and valleys (Figs. 11(a) and (b)) are due to the shock/ expansion process. The peak to peak distance in Fig. 11(b) for the rectangular jet is a good indication of the shock spacing. The work of Rice 
and Taghavi ${ }^{16}$ verified that even though the total pressure peaks occurred slightly downstream from the shocks, the shock spacing measured using a focussing schlieren system was the same as that measured from the pitot pressure traverses (peak-to-peak) along the jet axis. At a nozzle pressure ratio of 2.75 the total pressure for the oscillating flip-flop jet is slightly lower than that for the rectangular slot nozzle, whereas at a nozzle pressure ratio of 3.65 the pitot pressures for the non-oscillating flip-flop nozzle are significantly lower than that of the corresponding rectangular jet case.

Figure 12 shows static pressure measurements on the jet centerline within the flip-flop nozzle, and measurements from corresponding locations for the rectangular nozzle without the flip-flop attachment. The data is presented in the same format as in Fig. 11. The double cone static probe was used to measure $\mathrm{P}_{\text {st }}$, on the jet centerline. Figure 12(a) represents the case where the flip-flop jet was oscillating, whereas Fig. 12(b) represents the case where the flip-flop jet had stopped oscillating, and is attached to both walls of the flip-flop attachment. The centerline static pressures are lower for the flipflop jet than for the rectangular jet at both nozzle pressure ratios. For the flip-flop jet the abrupt static pressure recovery due to a possible shock is seen very clearly in Fig. 12(b).

Due to the obtrusive nature of the total and static pressure measurements and the complex nature of the confined supersonic flow within the flip-flop device, the data should be viewed, at best, as being qualitative.

\subsubsection{Comments on the Spreading of Supersonic} Flip-Flop Jets in Comparison to Rectangular Slot-Jets

Figure 13 shows the pitot pressure profiles measured in the $y$ direction at various $\mathrm{x} / \mathrm{h}$ locations for both the flip-flop jet and the rectangular jet. Figures 13(a) and (b) represent the profiles for the rectangular slot jet and the flipflop jet, respectively, at a nozzle pressure ratio of 2.75. Figures $13(\mathrm{c})$ and (d) shows the same type of data, but at a pressure ratio of 3.65 . Due to the shock/expansion pattern the profiles close to the nozzle exit cannot be used to make inferences about the spread of the jet. The profiles around $\mathrm{x} / \mathrm{h}=20$, however, should be a fair indication of the time-mean spread of the jet. For large downstream distances the static pressure can be assumed to be equal to the ambient pressure. The mass flux calculation for these cases can only be made if profiles in the y direction are measured at several $z$ stations at each $x / h$ location to provide detailed data defining the entire jet cross-section. This is necessary because at such large downstream distances the jet is no longer two-dimensional and the lateral spread of the jet could be a significant factor. The present work does not attempt to do this. At the Mach number where the flip-flop attachment has stopped oscillating (Fig. 13(d)), the flow is attached to both walls and the exit pressure profile shows a low pressure at the jet center, possibly due to a strong shock within the flip-flop device as mentioned earlier. This bifurcation effect persists downstream up to $\mathrm{x} / \mathrm{h}=10$. At $\mathrm{x} / \mathrm{h}=20$ the two peaks have merged to one.

While comparing the total pressure profiles for the rectangular slot jet and the oscillating flip-flop jet case (Figs. 13(a) and (b) and Figs. 13 (c) and (d)) it is essential to note that the rectangular slot jet is excited by its own screech. The effect of screech on the mixing of a supersonic jet has been shown previously ${ }^{14,15}$ to be very significant. For the spectral measurements shown in Fig. 14 a microphone was located very close to the nozzle lip, slightly upstream of the nozzle exit. At a pressure ratio of $2.75(\mathrm{M} \sim 1.3)$ three screech tones are seen to appear at 32.4, 33.6, and $35 \mathrm{KHz}$ (Fig. 14(a)). The Strouhal number range based on $h,(\operatorname{St}(h))$, is around 0.17 to 0.18 , a range where the shear layer is extremely sensitive to excitation. In addition, the large screech amplitudes ( $\sim 147$ to $154 \mathrm{~dB}$ ) could alter the spread of the rectangular slot jet significantly. In contrast, the microphone spectra for the oscillating flip-flop jet at the same nozzle pressure ratio, shown in the same figure, shows no screech tones. The enhanced spreading in Fig. 13(a) due to screech excitation for the simple rectangular jet is about the same as the pseudo-spreading in Fig. 13(b) due to the gross movement of the flip-flop jet. Thus, the increase in the time-mean spreading rate, which was seen very clearly for the subsonic 
flip-flop jet (Figs. 4(a) and (b) and 5(a)), is not seen here in Figs. 13(a) and (b).

Next, it is useful to compare the set of data in Figs. 13(c) and (d) for the rectangular slot nozzle and the non-oscillating flip-flop nozzle case (bifurcated velocity profile), both at a nozzle pressure ratio of 3.65 . Note that in going from Figs. 13(a) and (b) to Figs. 13(c) and (d) the nozzle pressure ratio was increased from 2.75 to 3.65. In Figs. 13(c) and (d) the total pressure data at $x / h=20$ indicate that the rectangular slot jet has in fact a higher spread than the flipflop nozzle non-oscillating case. For the rectangular slot jet one screech tone is seen at $21.2 \mathrm{KHz}$ $(\mathrm{St}(\mathrm{h})=0.12)$ with an amplitude of $159 \mathrm{~dB}$ (Fig. 14(b)). In comparison the flip-flop nonoscillating case has no screech tones. It was the observation of Krothapalli et al. ${ }^{15}$ that screech tones are most intense and have the greatest effect on the overall flowfield only in the range of pressure ratios from 3 to 4.5 . In their experiment the maximum screech sound radiation occurred at a nozzle pressure ratio of 3.8 . The pressure ratios for Figs. 14(a) and (b) are 2.75 and 3.65 respectively, the latter condition is close to that for maximum screech sound radiation. The screech data is also substantiated by schlieren flow visualization (not shown in this paper) using a focussing schlieren system. The rectangular slot jet shows shocks at a nozzle pressure ratio of $\mathbf{2 . 7 5}$ and stronger shocks at a nozzle pressure ratio of 3.65. Very weak shocks are seen outside the flip-flop nozzle for both oscillating (nozzle pressure ratio of 2.75 ) and non-oscillating (nozzle pressure ratio of 3.65 ) cases.

\section{Concluding Remarks}

(1) The subsonic flip-flop jet displayed a dramatically high time-mean spreading angle, which is deceptive due to the actual low frequency displacement of the jet between its two extremes. It was found that the total mass flux at any jet cross-section for both the rectangular slot nozzle (non-oscillating) and the flip-flop nozzle were about the same.

(2) It was found that it is possible to extend the operation of fluidically oscillated nozzles to supersonic flows. The oscillation of the flipflop jet extended smoothly from subsonic to supersonic flows. Confirmation was provided by flow visualization using high speed photography as well as unsteady velocity and pressure measurements. For a fixed nozzle geometry the oscillations stopped beyond a fully expanded Mach number of slightly over 1.58 , due to the attachment of the inner slot jet to both walls of the flip-flop attachment. Increasing the smaller dimension of the flip-flop attachment extended the operation of this nozzle to a fully expanded Mach number of 1.8 .

(3) The time-mean spreading of the supersonic flip-flop jet was not higher than that of the supersonic rectangular slot jet (non-oscillating). This was attributed to the underexpanded rectangular slot jet being self-excited by its own screech tones, and the absence of screech tones for the flip-flop jet.

(4) The main merit of the flip-flop nozzle seems to be its ability to produce large streamwise velocity perturbation levels. The flip-flop nozzle appears to have potential as an excitation device for exciting other flows.

\section{$\underline{\text { References }}$}

1. Crow, S.C., and Champagne, F.H., "Orderly Structure in Jet Turbulence," Journal of Fluid Mechanics, Vol. 48, 1971, pp. 547-591.

2. Ahuja, K.K., Lepicovsky, J., Tam, C.K.W., Morris, P.J., and Burrin, R.H., "ToneExcited Jet: Theory and Experiments," NASA CR-3538, 1982.

3. Ho, C.M., and Huang, L.S., "Subharmonics and Vortex Merging in Mixing Layers," Journal of Fluid Mechanics, Vol. 119, June 1982, pp. 443-473.

4. Raman, G., and Rice, E.J., "Axisymmetric Jet Forced by Fundamental and Subharmonic Tones," AIAA Journal, Vol. 29, July 1991, pp. 1114-1122.

5. Strange, P.J.R., and Crighton, D.G., "Spinning Modes on Axisymmetric Jets, Part 1," Journal of Fluid Mechanics, Vol. 134, Sept. 1983, pp. 231-245. 
6. Cohen, J., and Wygnanski, I., "The Evolution of Instabilities in the Axisymmetric Jet. Part 2. The Flow Resulting from the Interaction Between Two Waves," Journal of Fluid Mechanics, Vol. 176, Mar. 1987, pp. 221-235.

7. Raman, G., Rice, E.J., and Reshotko, E., "Control of an Axisymmetric Turbulent Jet by Multi-Modal Excitation," NASA TM-104483, 1991.

8. Raman, G., Zaman, K.B.M.Q., and Rice, E.J., "Initial Turbulence Effect on Jet Evolution with and without Tonal Excitation," Physics of Fluids A, Vol. 1, July 1989, pp. 1240-1248.

9. Binder, G., and Favre-Marinet, M., "Mixing Improvement in Pulsating Turbulent Jets," Fluid Mechanics of Mixing; Proceedings of the Joint Meeting of the American Society of Mechanical Engineers, ASME, New York, 1973, pp. 167-172.

10. Rockwell, D.O., "External Excitation of Planar Jets," Journal of Applied Mechanics, Vol. 39, Apr. 1972, pp. 883-890.

11. Strykowski, P.J., and Wilcoxon, R.K., "Self-Excitation and Mixing in Axisymmetric Jets with Counterflow," AIAA Paper 92-0538, 1992.

12. Hill W.G., and Greene, P.R., "Increased Turbulent Jet Mixing Rates Obtained by Self-Excited Acoustic Oscillations," Transactions of the ASME, June 1977, pp. 520-525.

13. Hussain, A.K.M.F., and Hasan, M.A.Z., "The 'Whistler-Nozzle' Phenomenon," Journal of Fluid Mechanics, Vol. 134, Sept. 1983, pp. 431-458.

14. Glass, D.R., "Effects of Acoustic Feedback on the Spread and Decay of Supersonic Jets," AIAA Journal, Vol. 6, Oct. 1968, pp. $1890-1897$.
15. Krothapalli, A., Hsia, Y., Baganoff, D., and Karamcheti, K., "The Role of Screech Tones in Mixing of an Underexpanded Rectangular Jet," Journal of Sound and Vibration, Vol. 106, Apr. 1986, pp. 119-143.

16. Rice, E.J., and Taghavi, R., "Screech Noise Source Structure of a Supersonic Rectangular Jet," AIAA Paper 92-0503, 1992.

17. Viets, H., "Flip Flop Jet Nozzle," AIAA Journal, Vol. 13, Oct. 1975, pp. 1375-1379.

18. Viets, H., Piatt, M., Ball, M., Bethke, R.J., and Bougine, D., "Problems in Forced Unsteady Fluid Mechanics," AFWAL TM-81-148, 1981.

19. Vlasov, Y.V., and Ginevskiy, A.S., "Generation and Suppression of Turbulence in an Axisymmetric Turbulent Jet in the Presence of an Acoustic Influence," NASA TT-F-15, 721, 1974.

20. Zaman, K.B.M.Q., and Hussain, A.K.M.F., "Turbulence Suppression in Free Shear Flows by Controlled Excitation," Journal of Fluid Mechanics, Vol. 103, Feb. 1981, pp. 133-159.

21. Zaman, K.B.M.Q., Samimy, M., and Reeder, M.F., "Effect of Tabs on the Evolution of an Axisymmetric Jet," NASA TM-104472, 1991.

22. Pinckney, S.Z., "A Short Static-Fressure Probe Design for Supersonic Flow," NASA TN-D 7978, 1975.

23. Simmons, J.M., Platzer, M.F., and Smith, T.C., "Velocity Measurements in an Oscillating Plane Jet Issuing into a Moving Stream," Journal of Fluid Mechanics, Vol. 84, 1978, pp. 33-53. 
24. Fiedler, H., and Korschelt, D., "The TwoDimensional Jet with Periodic Initial Condition," Proceedings of the Second Symposium on Turbulent Shear Flows, Imperial College, London, pp. 8.18-8.23, 1979.

25. Srinivas, T., Vasudevan, B., and Prabhu, A., "Performance of Fluidically Controlled
Oscillating Jet", Turbulence Management and Relaminarization; IUTAM Symosium, Bangalore India, 1987, edited by H.W. Liepmann and R. Narasimha, Springer-Verlag, New York, pp. 487-494, 1988. 
Table 1. - Summary of Nozzle Dimensions

[For all nozzles, $\mathrm{L}_{\mathrm{ff}}=15.87, \mathrm{~L}=290, \mathrm{~d}=12.7$. All dimensions are in $\mathrm{mm}$.

\begin{tabular}{|l|c|c|c|l|c|c|c|c|}
\hline \multicolumn{1}{|c|}{ Nozzle } & $\mathrm{h}$ & $\mathrm{b}$ & $\mathrm{s}=\mathrm{b} / \mathrm{h}$ & Geometry & $\mathrm{H}$ & $\mathrm{B}$ & $\mathrm{s}=\mathrm{b} / \mathrm{h}$ & $\mathrm{w}$ \\
\hline I SUBSONIC & 4.76 & 37.3 & 7.83 & $\begin{array}{l}\text { Parallel } \\
\text { walls }\end{array}$ & 9.52 & 37.3 & 3.91 & 4.76 \\
\hline II SUPERSONIC & 2.34 & 19.05 & 8.15 & $\begin{array}{l}\text { Parallel } \\
\text { walls }\end{array}$ & 5.56 & 21.4 & 3.85 & 3.17 \\
\hline III SUPERSONIC & 2.34 & 19.05 & 8.15 & $\begin{array}{l}\text { Parallel } \\
\text { walls }\end{array}$ & 7.94 & 21.4 & 2.7 & 3.17 \\
\hline IV SUPERSONIC & 2.34 & 19.05 & 8.15 & $\begin{array}{l}\text { Divergent } \\
\text { walls } \\
5^{\circ} \text { half } \\
\text { angle }\end{array}$ & 7.94 & 21.4 & 2.7 & 3.17 \\
\hline
\end{tabular}

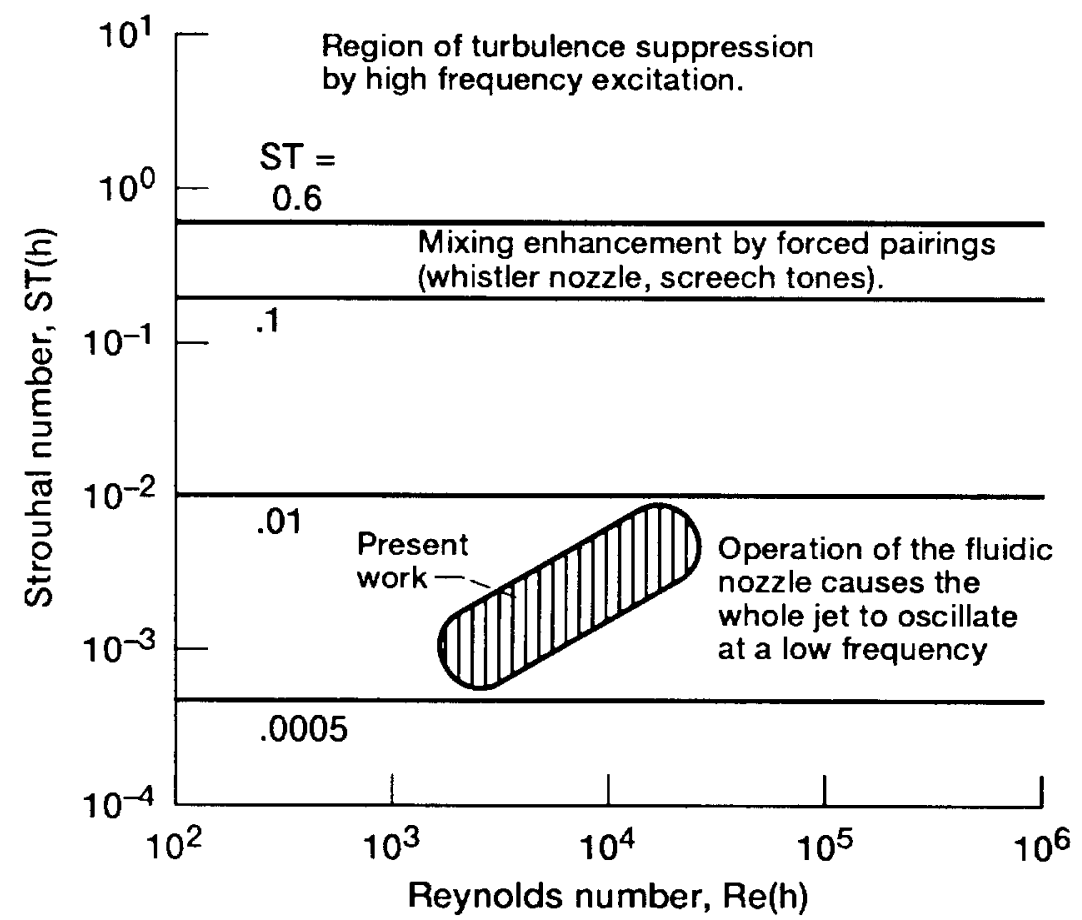

Figure 1.-Regimes of perturbed jets. (Adapted from Rockwell ${ }^{10}$ ) 

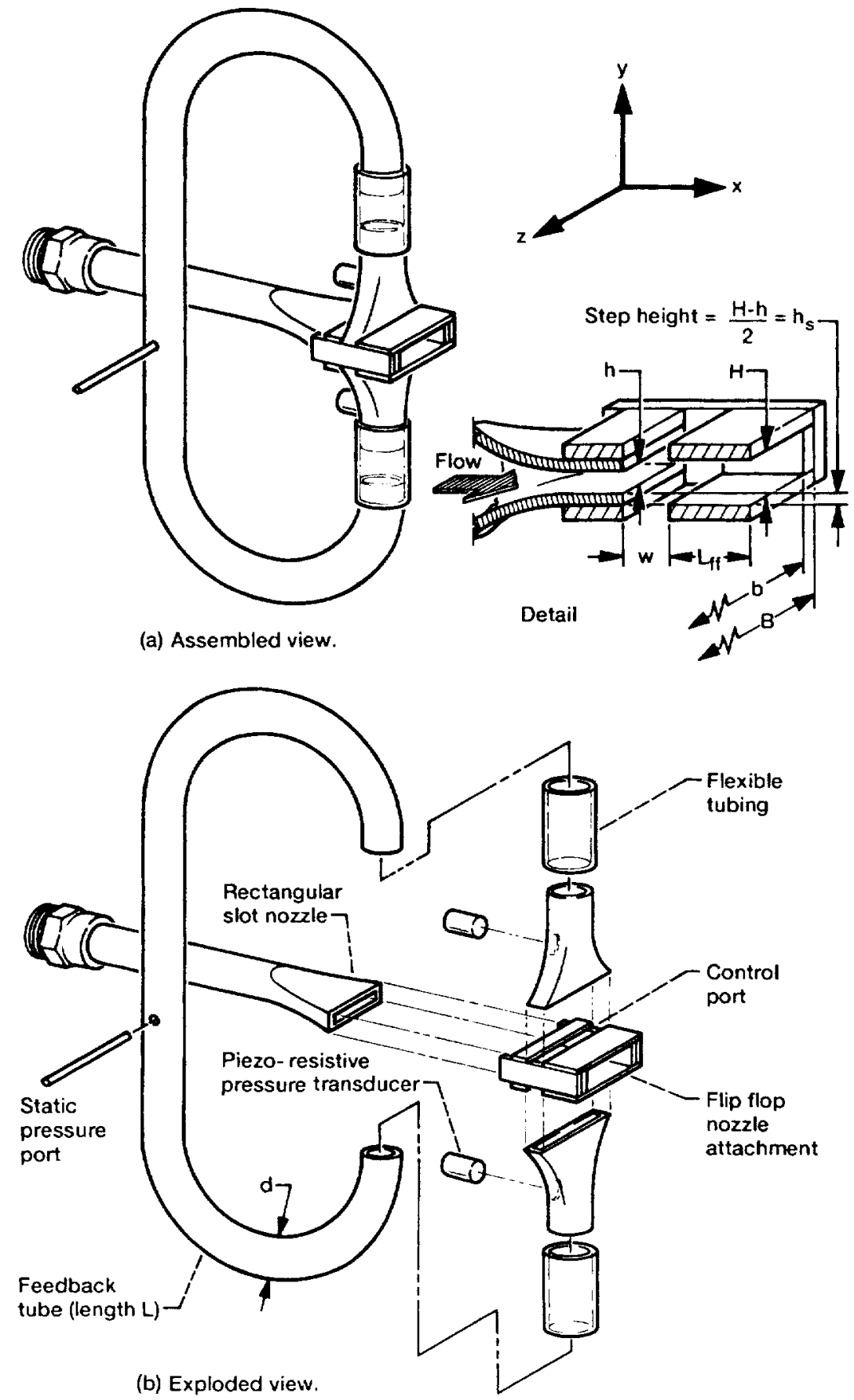

Figure 2.-Schematic of the flip-flop nozzle. 


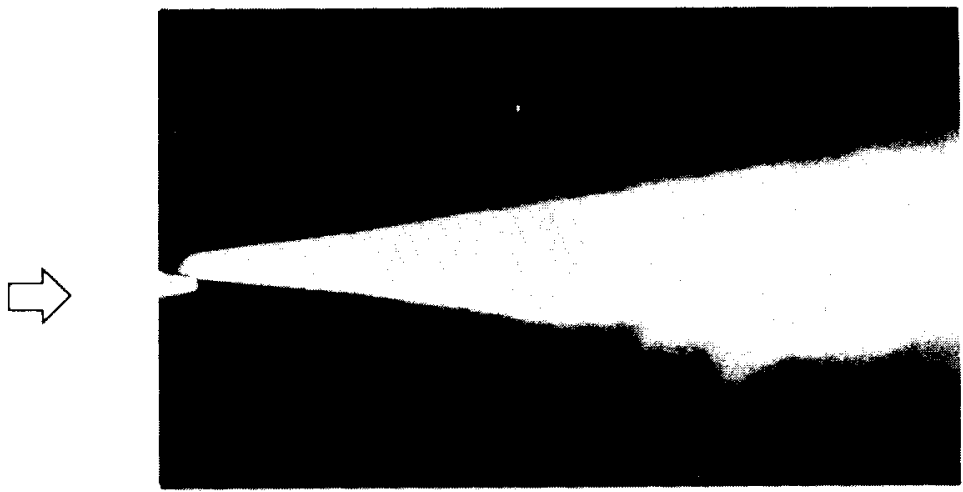

(a)

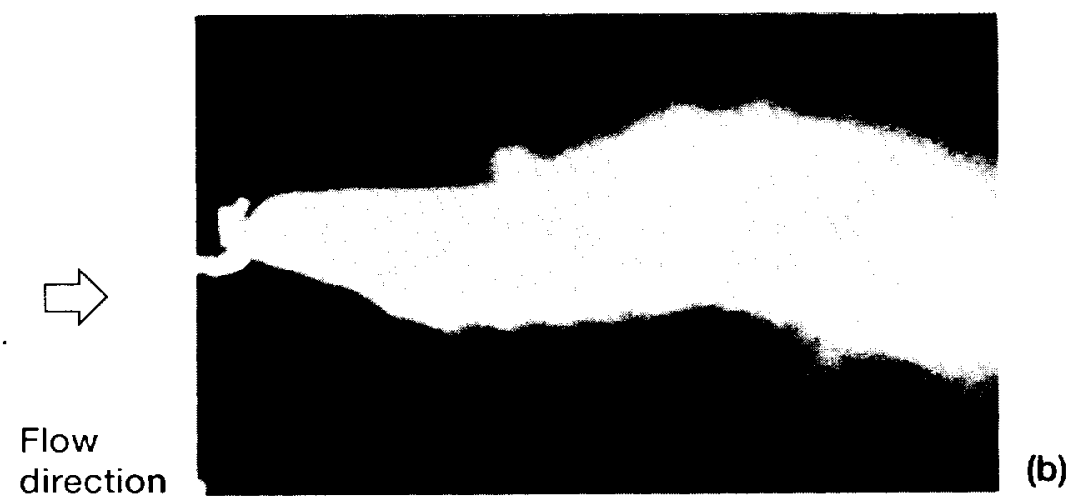

Figure 3.-Smoke flow visualization of subsonic jets using high speed photography. (a) Rectangular slot nozzle, $M=0.3$ and (b) flip-flop nozzle, $M=0.3$. 


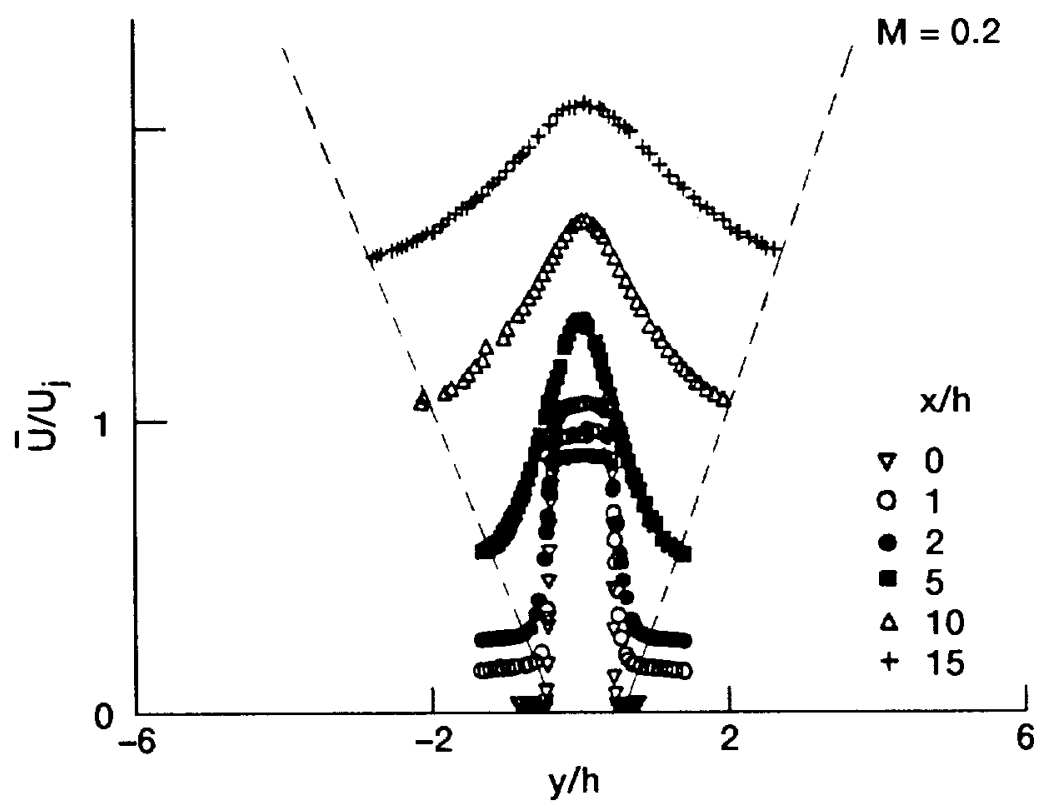

(a) Rectangular slot nozzle.

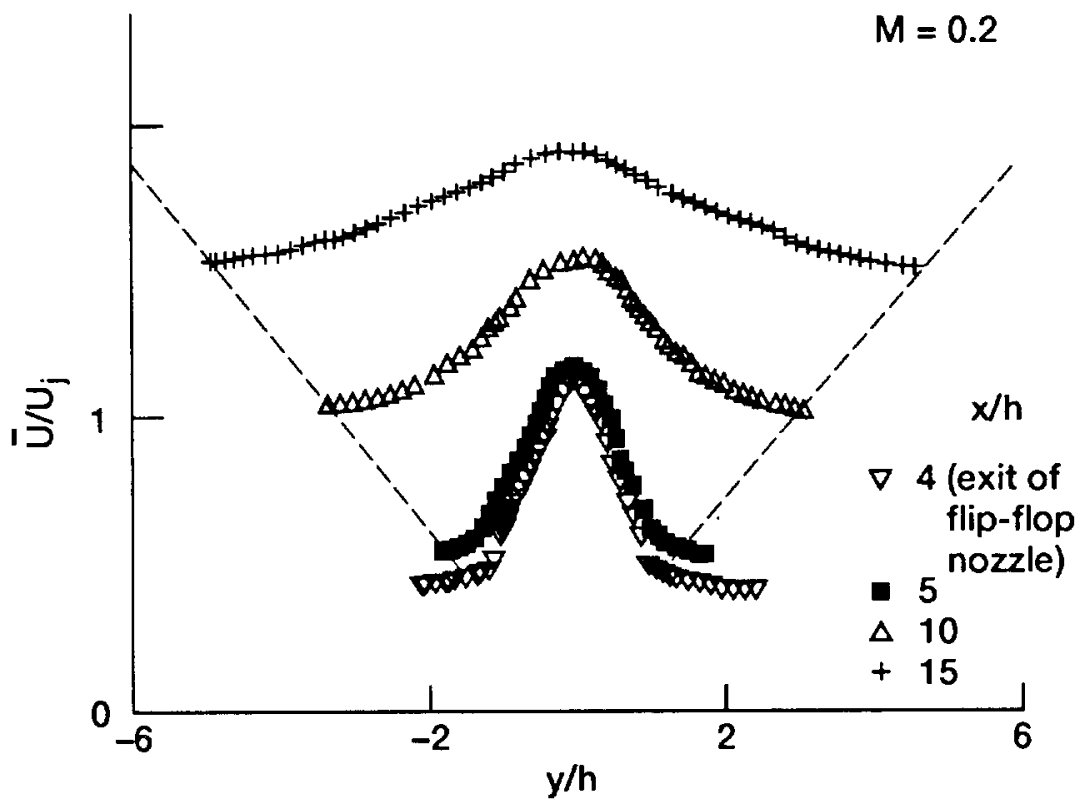

(b) Flip-flop nozzle.

Figure 4.-Evolution of mean velocity profiles. 


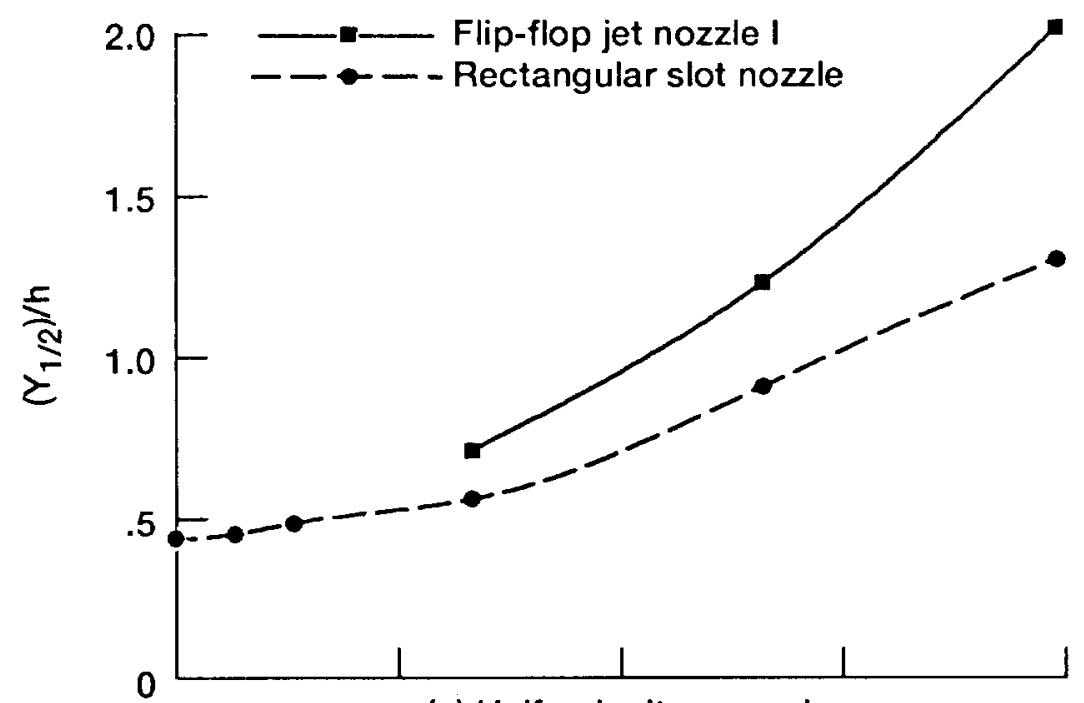

(a) Half-velocity spread.

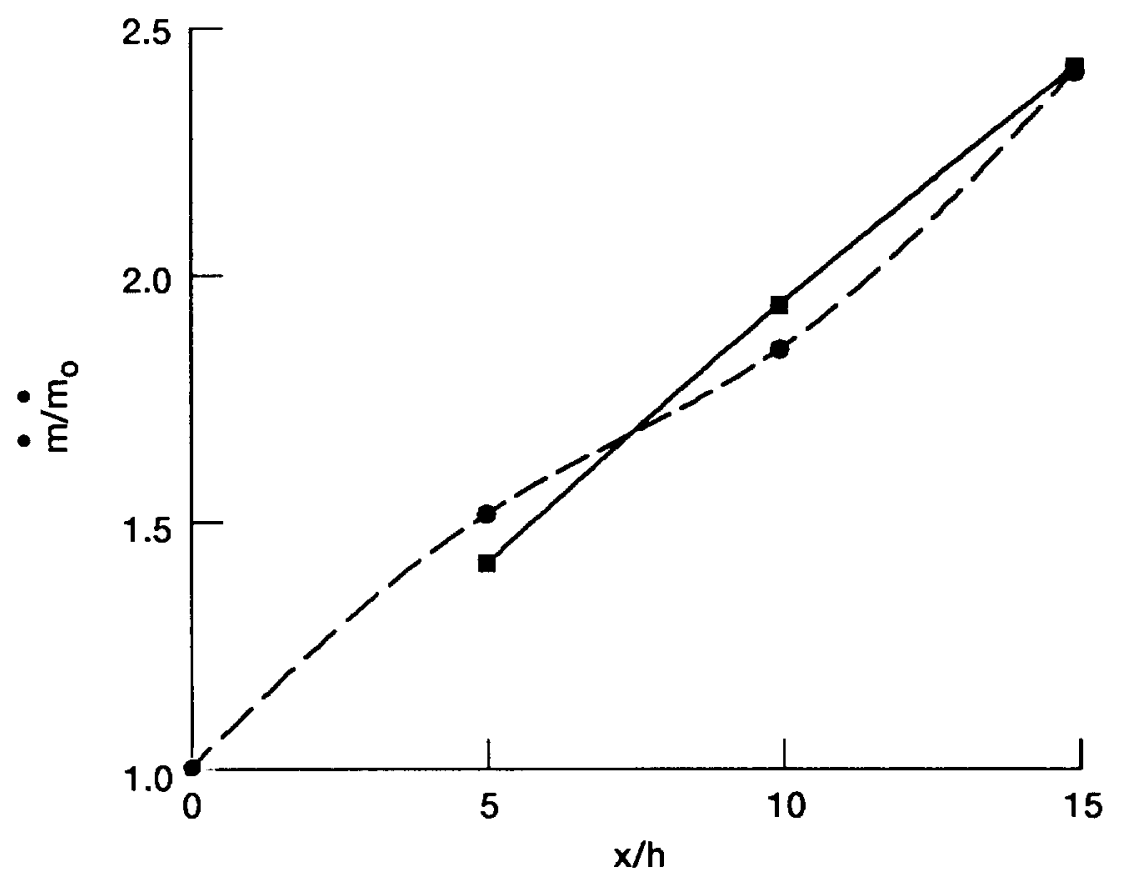

(b) Mass flux ratio.

Figure 5.-Variation of jet spread and mass flux with axial distance. 

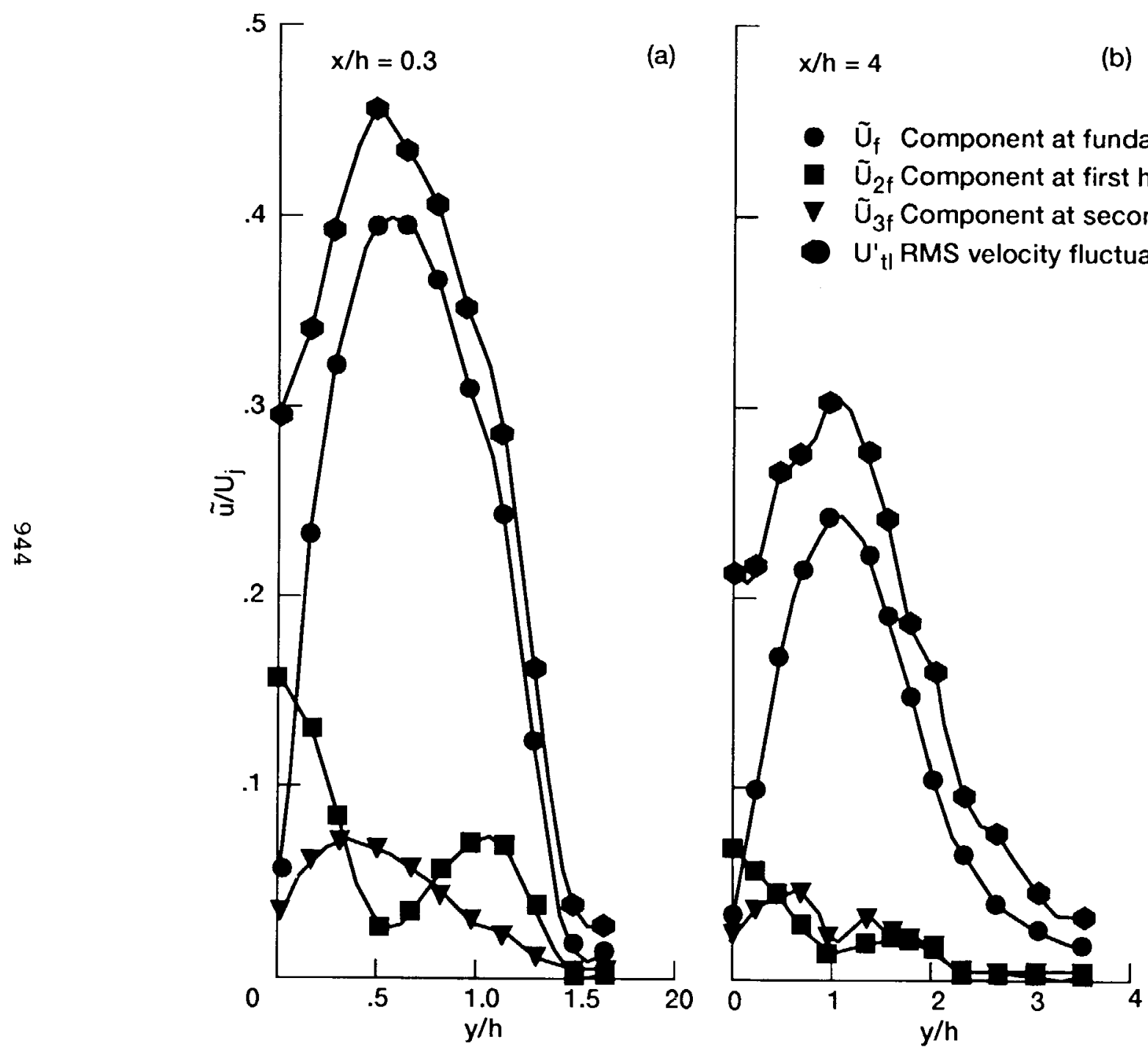

(b) $\prod_{x / h=26}$

- $\tilde{U}_{f}$ Component at fundamental flapping frequency

- $\tilde{U}_{2 \mathrm{f}}$ Component at first harmonic of flapping frequency

$\nabla \tilde{U}_{3 f}$ Component at second harmonic of flapping frequency

U ${ }_{t \mid} R M S$ velocity fluctuations in the jet (total)

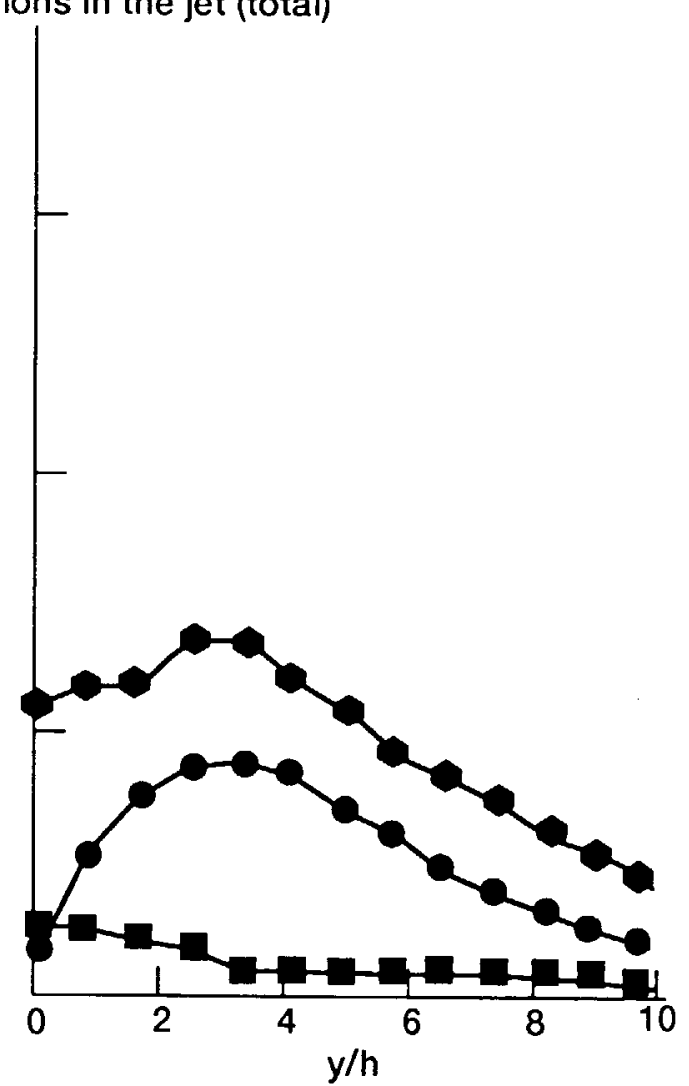

Figure 6.-Radial variation of phase averaged unsteady velocity components. 

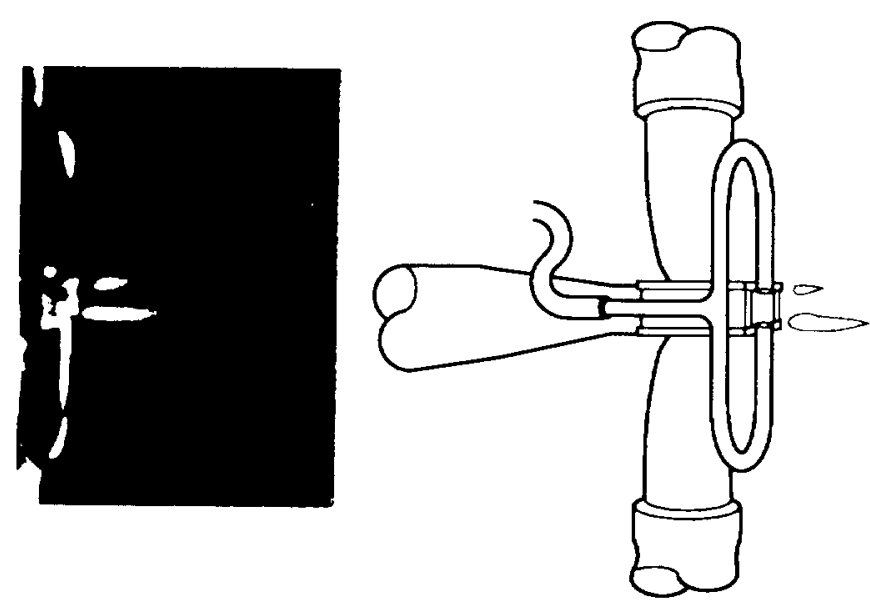

(a) Phase 1 of oscillation, $M=1.58$.
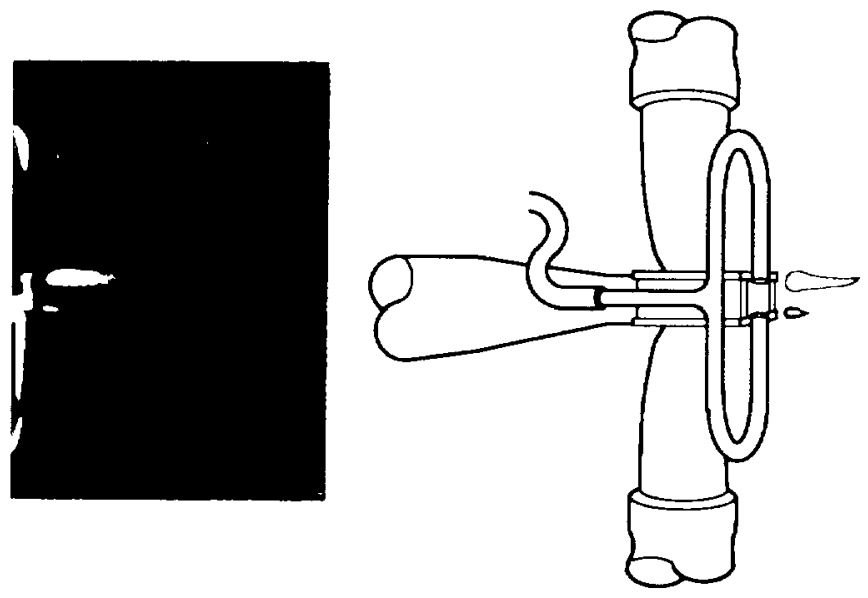

(b) Phase 2 of oscillation, $M=1.58$.
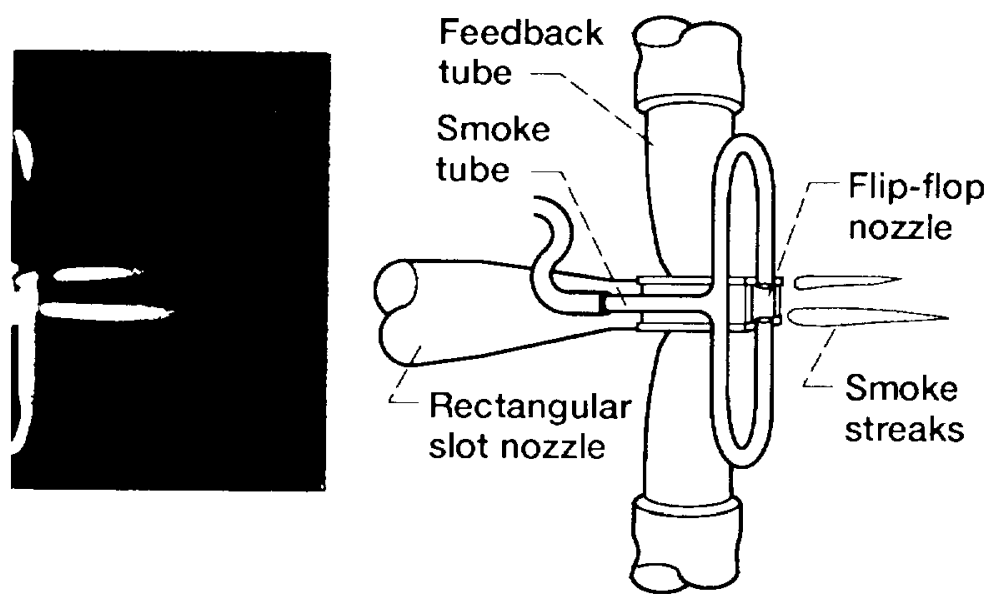

(c) Non-oscillating case, $M=1.9$.

Figure 7.-Smoke flow visualization of a supersonic flipflop jet using high speed photography. 


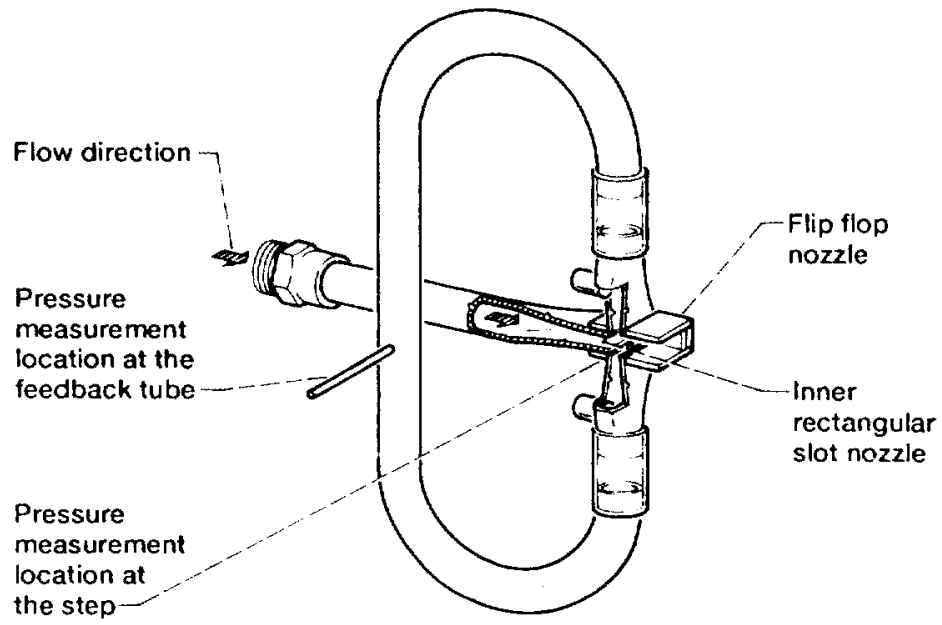

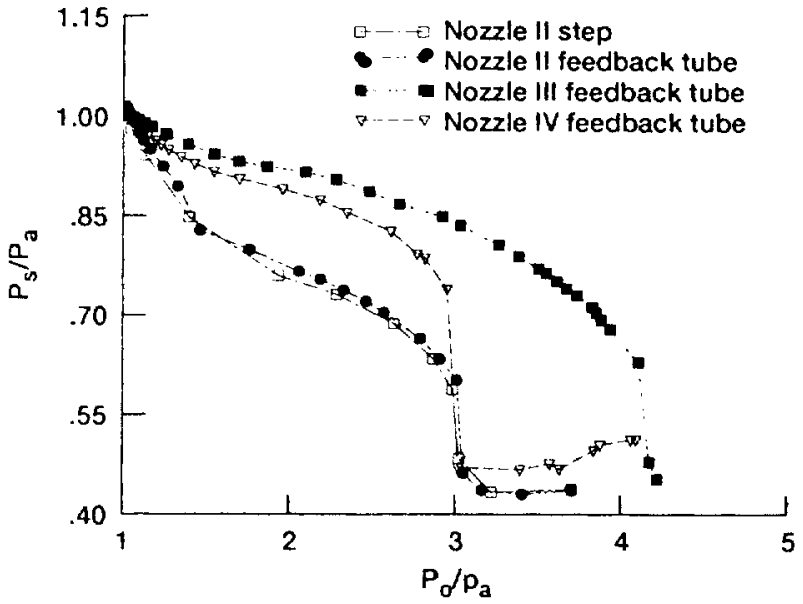

(a) Pressure measured in the feedback tube for various nozzle pressure ratios.

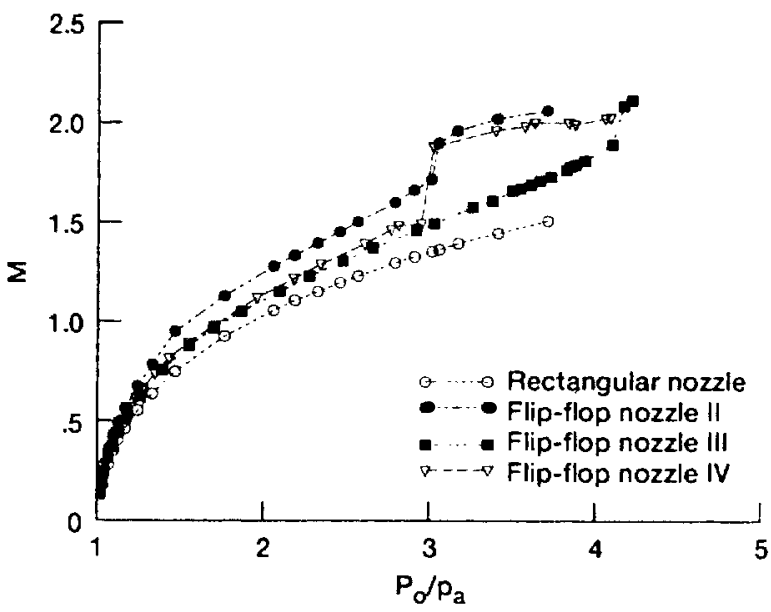

(b) Mach number versus nozzle pressure ratio.

Figure 8.-Feedback tube pressure and jet Mach number for various nozzle pressure ratios. 

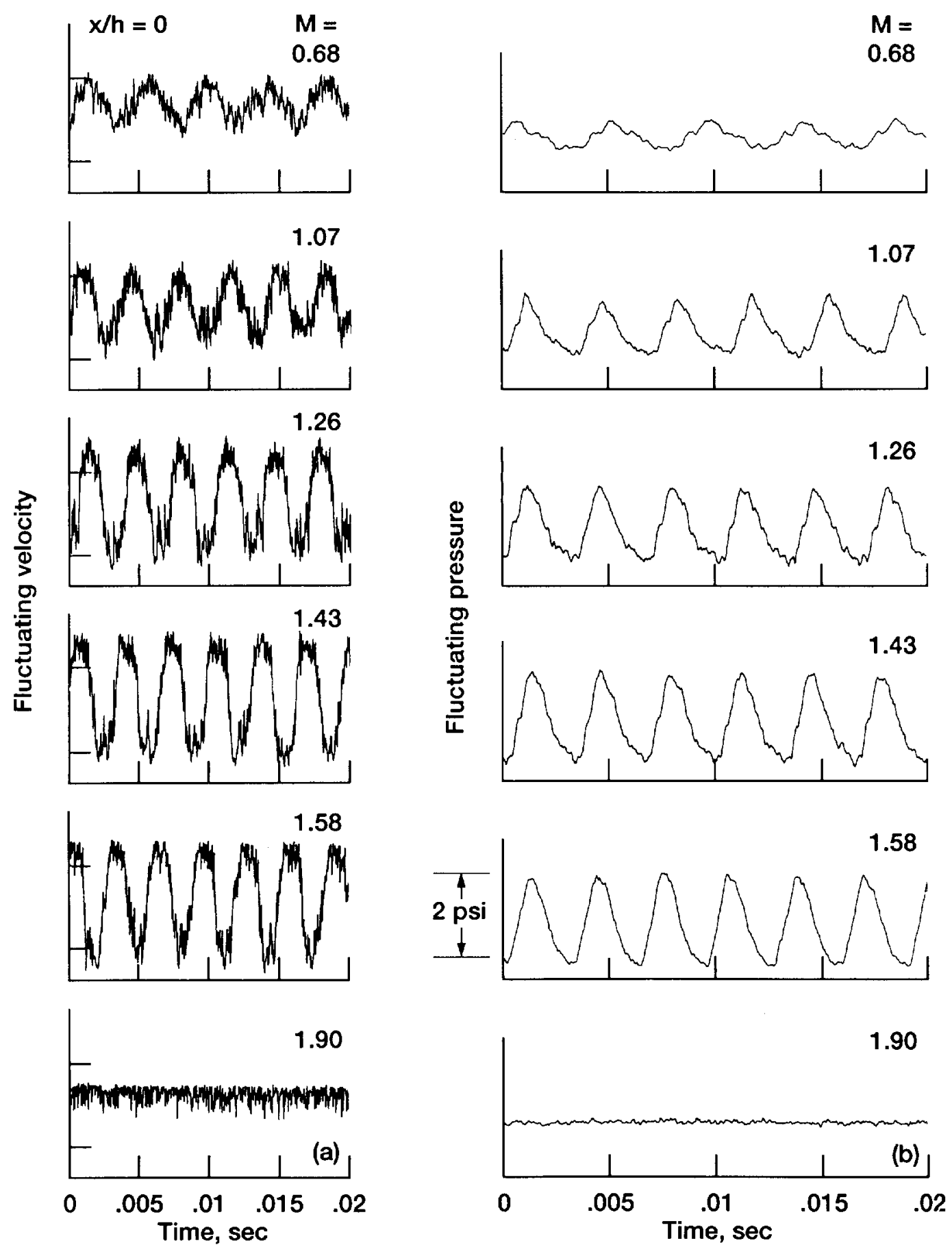

Figure 9.-Time traces. (a) Velocity signal at the exit of the flip-flop jet and (b) Pressure signal in feedback tube for various Mach numbers. 


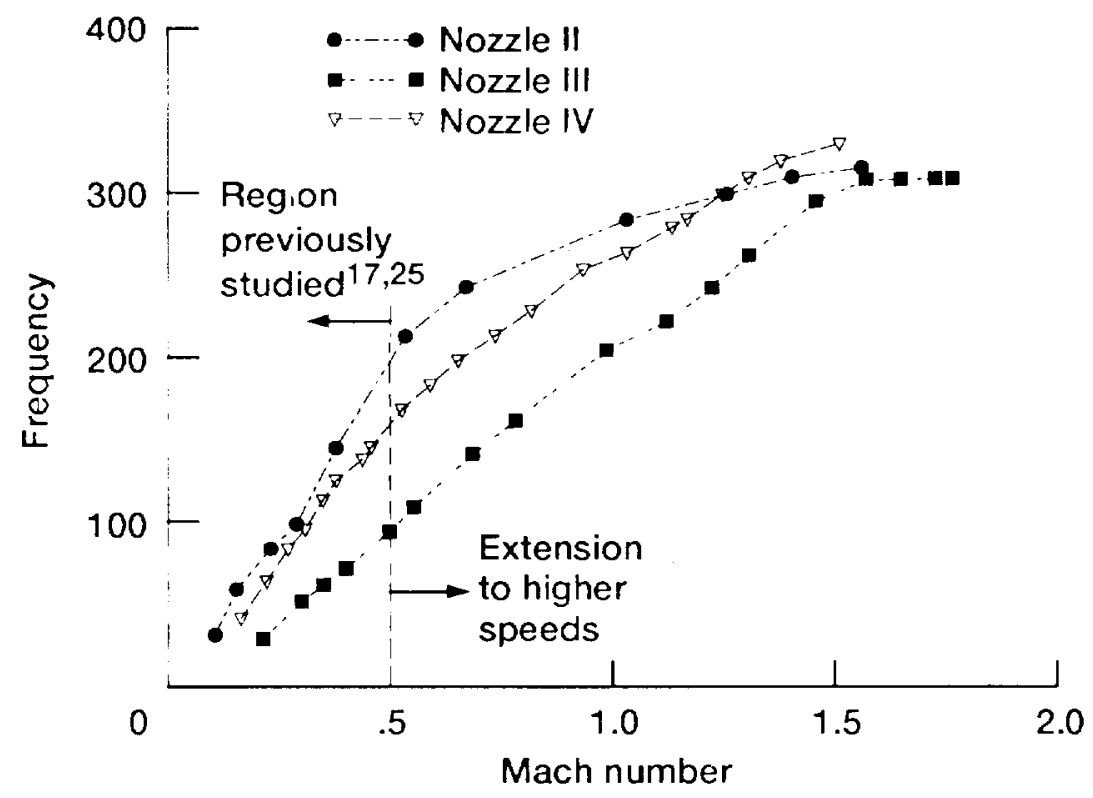

Figure 10.-Frequency of oscillation of the flip-flop nozzle versus Mach number. 


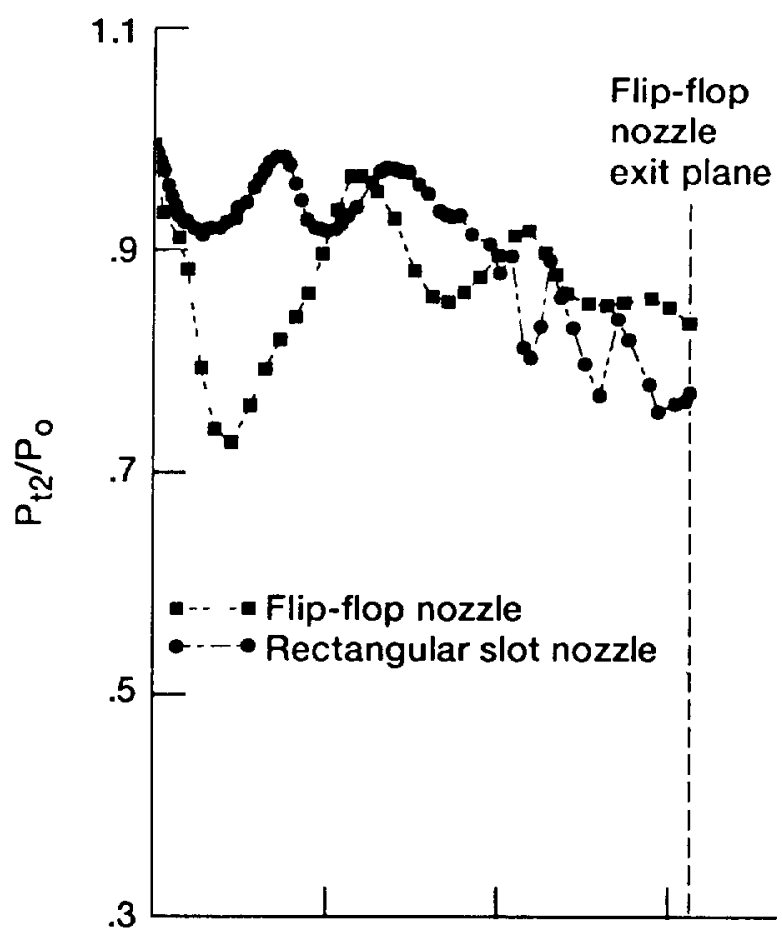

(a) Nozzle pressure ratio $=2.75$

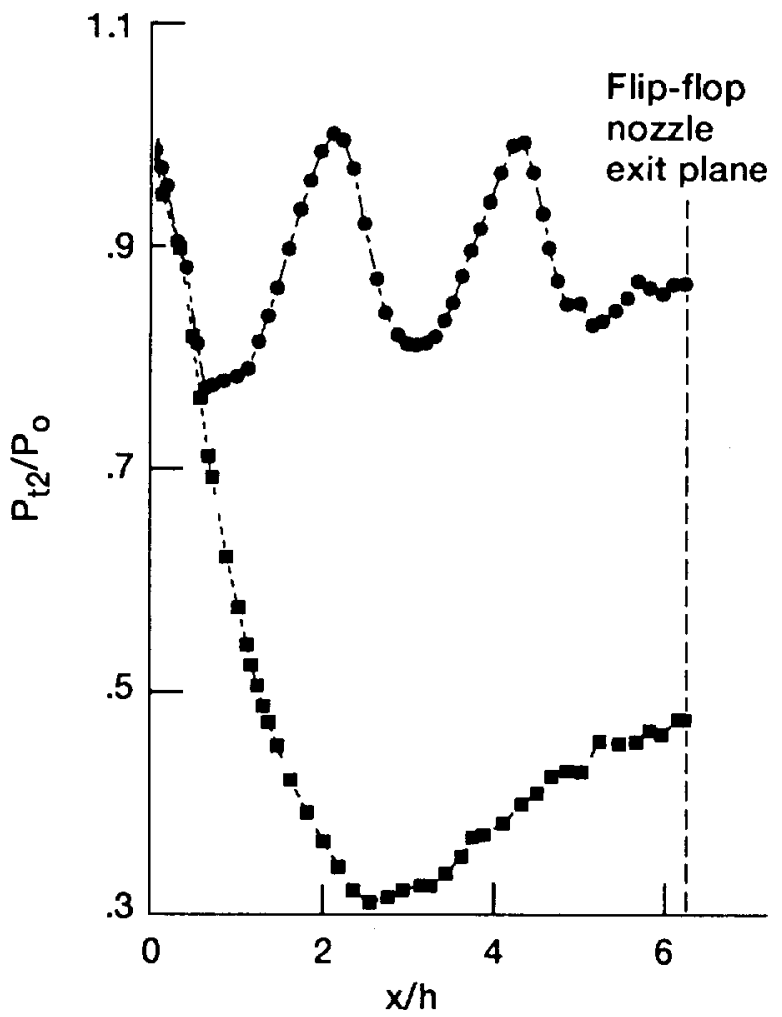

(b) Nozzle pressure ratio $=3.65$

Figure 11.-A comparison of the axial pitot pressure variation with in the flip-flop nozzle with that of a rectangular slot nozzle.

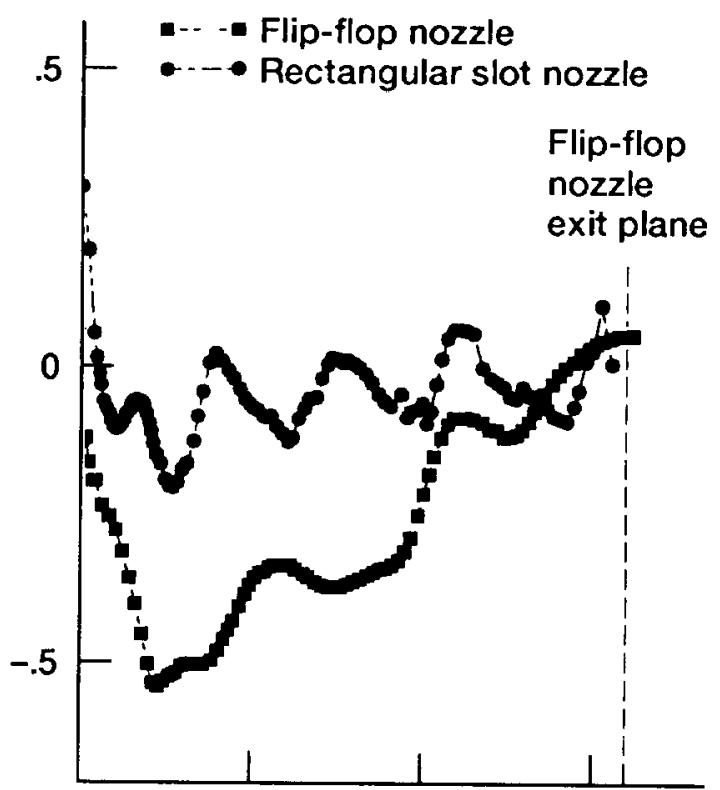

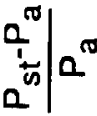

(a) Nozzle pressure ratio $=2.75$

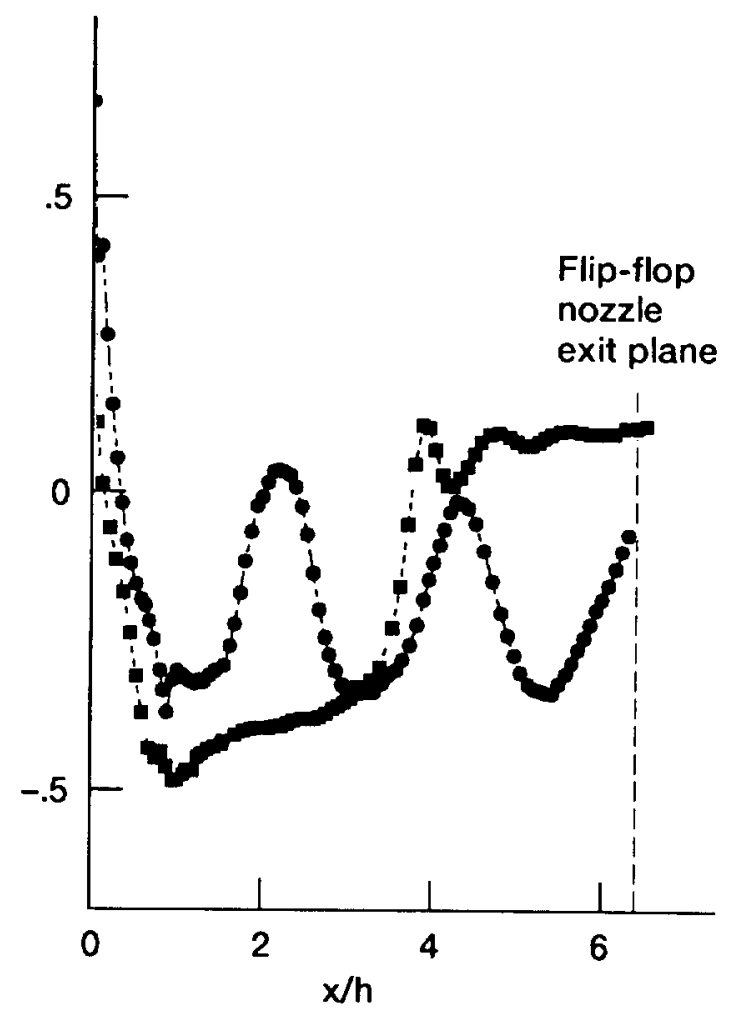

(b) Nozzle pressure ratio $=3.65$

Figure 12.-A comparison of the axial static pressure variation within the flip-flop nozzle with that of a rectangular slot nozzle. 


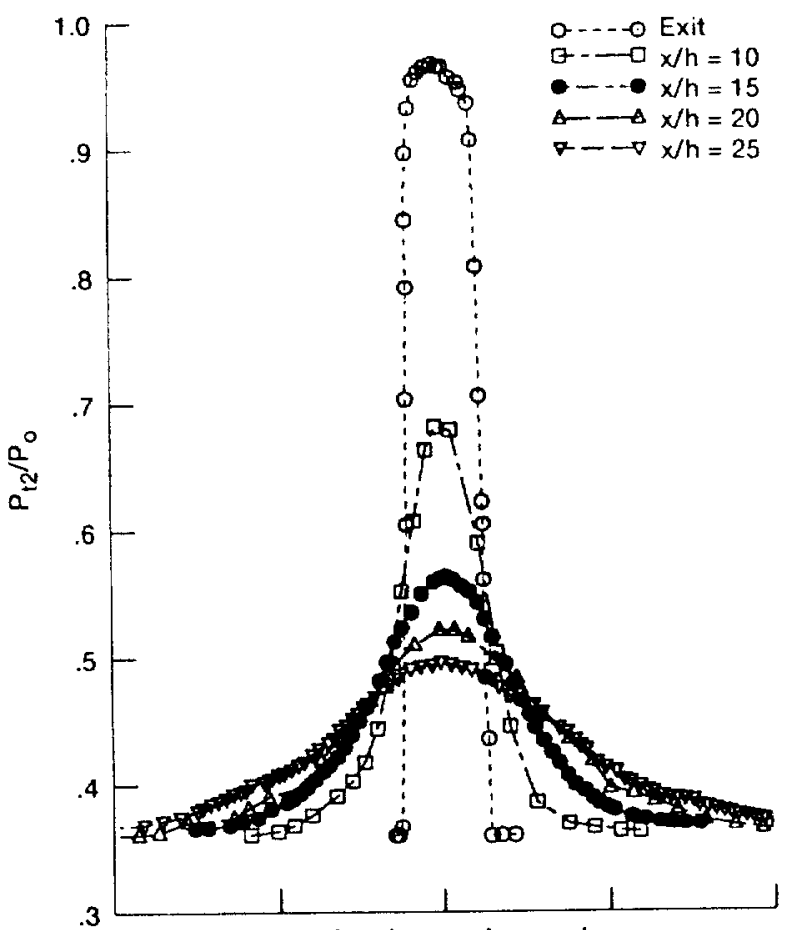

(a) Rectangular slot nozzle, nozzle pressure ratio $=2.75, M=1.3$.

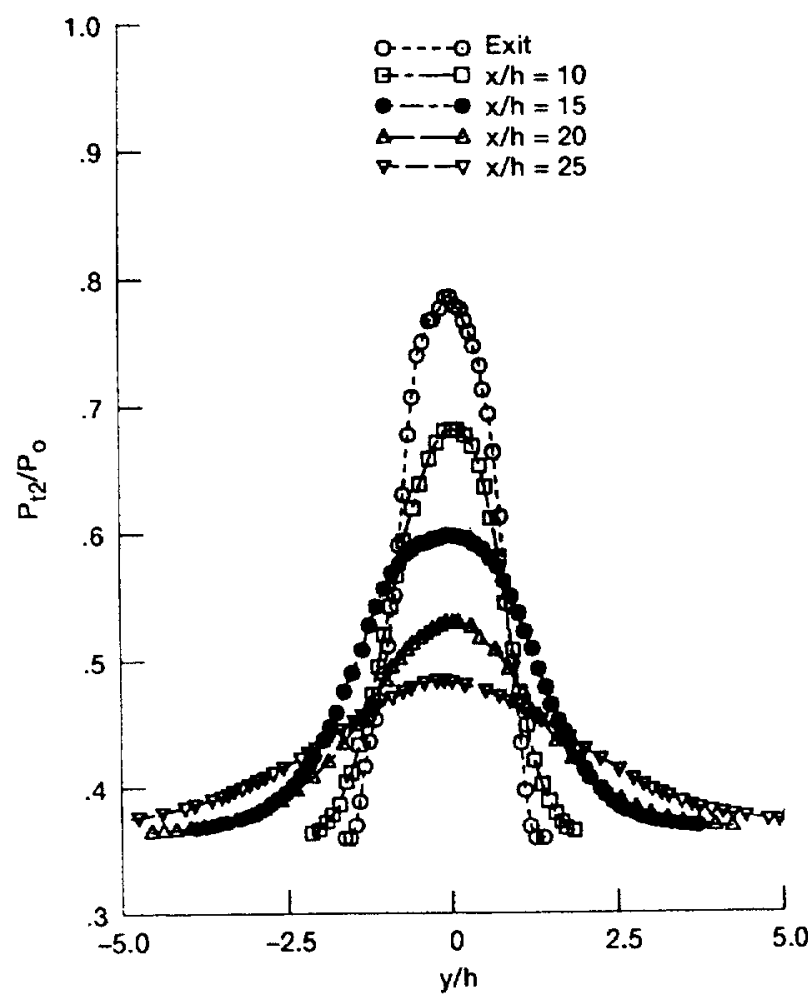

(b) Flip-flop nozzle, nozzle pressure ratio $=2.75, M=1.58$.
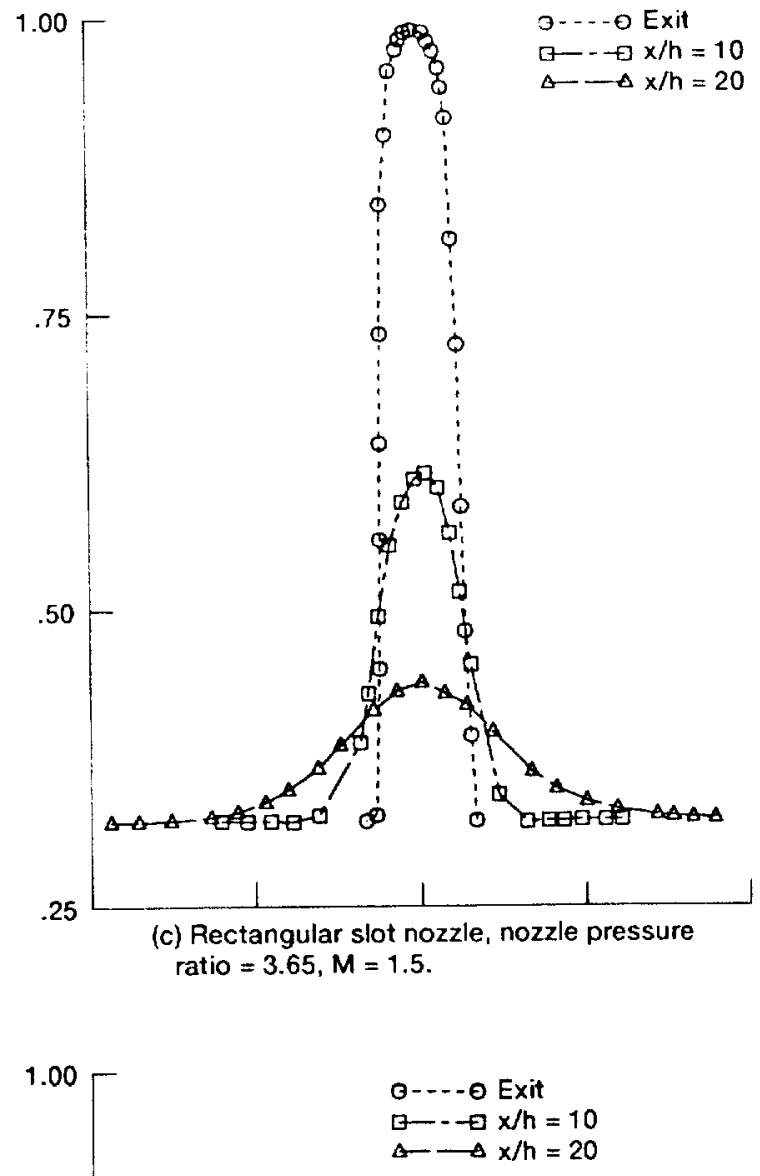

Figure 13.-Pitot pressure profiles. 


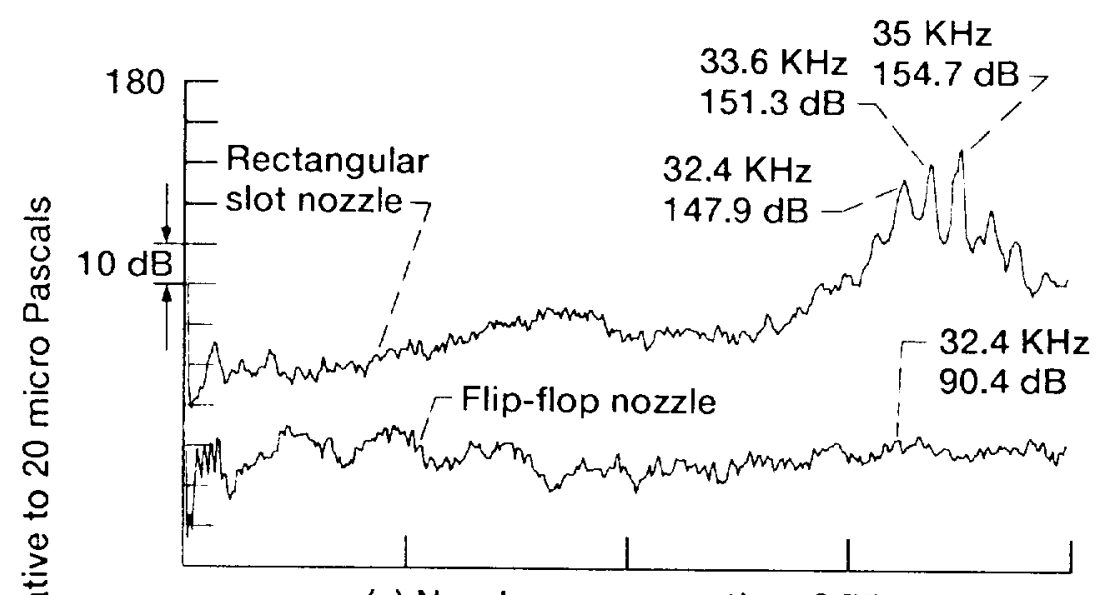

(a) Nozzle pressure ratio $=2.75$.

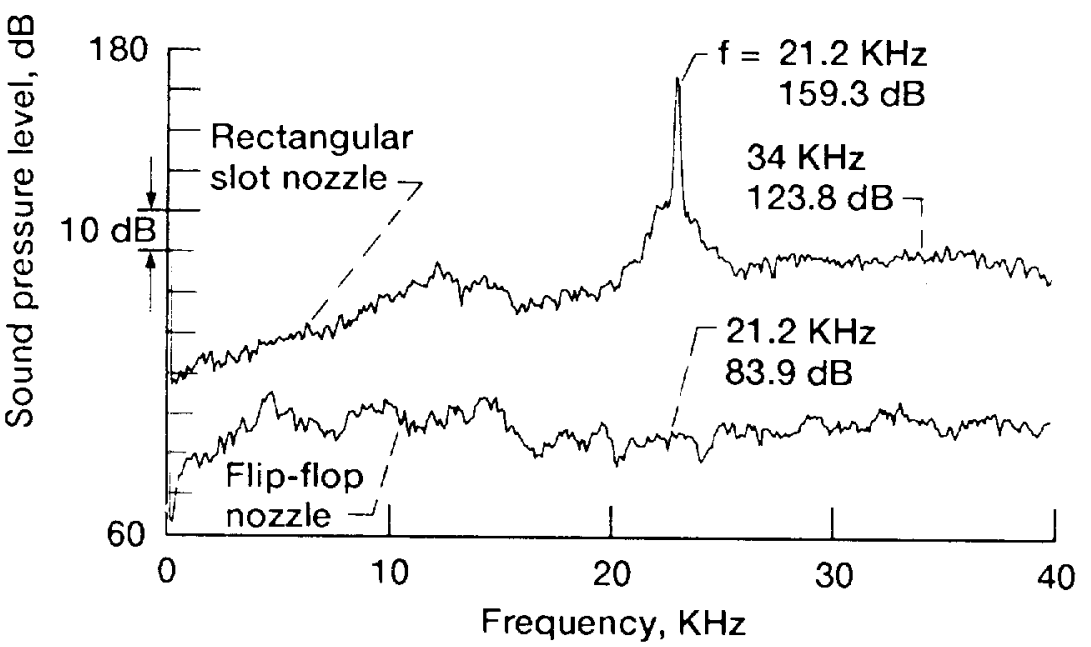

(b) Nozzle pressure ratio $=3.65$.

Figure 14.-Sound pressure spectra. 